bioRxiv preprint doi: https://doi org/10.1101/2020 08.07.241794; this version posted August 7,2020 . The copyright holder for this preprint (which was not certified by peer review) is the author/funder, who has granted bioRxiv a license to display the preprint in perpetuity. It is made available under aCC-BY-ND 4.0 International license.

\title{
BODY MASS VARIATIONS RELATE TO FRACTIONATED FUNCTIONAL BRAIN HIERARCHIES
}

Bo-yong Park ${ }^{\mathrm{a}}$, Hyunjin Park ${ }^{\mathrm{b}, \mathrm{c}}$, Filip Morys ${ }^{\mathrm{a}}$, Mansu Kim ${ }^{\mathrm{d}}$, Kyoungseob Byeon ${ }^{\mathrm{c}, \mathrm{e}}$, Hyebin Lee ${ }^{\mathrm{c}, \mathrm{e}}$, SeHong Kim ${ }^{\mathrm{f}}$, Sofie Valk ${ }^{\mathrm{g}}$, Alain Dagher ${ }^{\mathrm{a}}$, Boris C. Bernhardt ${ }^{\mathrm{a}}$

${ }^{a}$ McConnell Brain Imaging Centre, Montreal Neurological Institute and Hospital, McGill University, Montreal, QC, Canada; ${ }^{b}$ School of Electronic and Electrical Engineering, Sungkyunkwan University, Suwon, South Korea; ${ }^{c}$ Center for Neuroscience Imaging Research, Institute for Basic Science, Suwon, South Korea; ${ }^{d}$ Department of Biostatistics, Epidemiology, and Informatics, University of Pennsylvania, Philadelphia, United States of America; ${ }^{e}$ Department of Electrical and Computer Engineering, Sungkyunkwan University, Suwon, South Korea ${ }^{f}$ Department of Family Medicine, St. Vincent's Hospital, Catholic University College of Medicine, Suwon, South Korea; ' ${ }^{\circ}$ Otto Hahn Research Group for Cognitive Neurogenetics, Max Planck Institute for Cognitive and Brain Sciences, Leipzig, Germany

\section{*Corresponding Authors:}

Boris C. Bernhardt, $\mathrm{PhD}$

Multimodal Imaging and Connectome Analysis Lab

McConnell Brain Imaging Centre

Montreal Neurological Institute and Hospital

McGill University

Montreal, Quebec, Canada

Phone: +1-514-398-3579

Email: boris.bernhardt@mcgill.ca

Bo-yong Park, $\mathrm{PhD}$

Multimodal Imaging and Connectome Analysis Lab

McConnell Brain Imaging Centre

Montreal Neurological Institute and Hospital

McGill University

Montreal, Quebec, Canada

Email: bo.y.park@mcgill.ca 


\begin{abstract}
Variations in body mass index (BMI) have been suggested to relate to atypical brain organization, yet connectome-level substrates of BMI and their neurobiological underpinnings remain unclear. Studying 325 healthy young adults, we examined association between functional connectome organization and BMI variations. We capitalized on connectome manifold learning techniques, which represent macroscale functional connectivity patterns along continuous hierarchical axes that dissociate low level and higher order brain systems. We observed an increased differentiation between unimodal and heteromodal association networks in individuals with higher BMI, indicative of an increasingly segregated modular architecture and a disruption in the hierarchical integration of different brain system. Transcriptomic decoding and subsequent gene enrichment analyses identified genes previously implicated in genome-wide associations to BMI and specific cortical, striatal, and cerebellar cell types. These findings provide novel insights for functional connectome substrates of BMI variations in healthy young adults and point to potential molecular associations.
\end{abstract}

KEYWORDS: body mass index; functional connectome; manifold; transcriptomic analysis 
bioRxiv preprint doi: https://doi.org/10.1101/2020.08.07.241794; this version posted August 7, 2020. The copyright holder for this preprint (which was not certified by peer review) is the author/funder, who has granted bioRxiv a license to display the preprint in perpetuity. It is made available under aCC-BY-ND 4.0 International license.

Park et al. | Functional connectome substrates of BMI variations

\section{INTRODUCTION}

A high body mass index (BMI) has been recognized as one of the most significant contributors to adverse health and psychological outcomes (Blüher, 2019; James, 2008; World Health Organization, 2020). High BMI is an indicator of obesity, a condition with increasing prevalence worldwide (World Health Organization, 2020) and a critical factor in the development of type 2 diabetes, cardiovascular disease, stroke, cancer, and metabolic syndrome (Jensen et al., 2014; Malik et al., 2013; Raji et al., 2010; Val-Laillet et al., 2015). In addition, multiple neurobiological processes related to obesity have been recognized, including mechanisms regulating eating behaviors, together with genetic and transcriptomic underpinnings (Locke et al., 2015; Martin et al., 2010; Murray et al., 2014; Van Opstal et al., 2018; Steward et al., 2019a; Vainik et al., 2013, 2018; Val-Laillet et al., 2015; Verdejo-Román et al., 2017; Ziauddeen et al., 2015).

Neuroimaging techniques, particularly magnetic resonance imaging (MRI), can identify cerebral substrates associated with BMI by tapping into whole-brain structure, function, and connectivity. Prior structural MRI research has shown that measures of cortical and subcortical morphology robustly correlate with BMI variations in healthy (Herrmann et al., 2019; Marqués-Iturria et al., 2013; Shott et al., 2015; Vainik et al., 2018) and diseased samples (King et al., 2018; Olivo et al., 2017). Multiple task-based functional MRI studies have also shown associations between BMI and brain activations in impulse control and reward processing paradigms (Brooks et al., 2013; Goldstone et al., 2009; Gupta et al., 2018; Van Meer et al., 2019; Opel et al., 2015; Park et al., 2017; Steward et al., $2019 \mathrm{~b}$; Stoeckel et al., 2008). On the other hand, functional signatures of BMI at macroscale during resting conditions remain underexplored. Indeed, despite reports exploring associations between BMI and the connectivity of specific regions (García-García et al., 2015; Lips et al., 2014; Park et al., 2015) and larger networks (García-García et al., 2013; Park et al., 2016), whole-brain functional network configurations associated with BMI are less well established. We aim to close this gap in the current work by applying connectome manifold learning techniques to identify functional substrates of BMI in a large population of healthy adults. One appealing feature of these techniques is that they compress high-dimensional connectomes into sets of lower-dimensional eigenvectors that visualize principles of inter-regional connectivity (Margulies et al., 2016). These maps specifically depict the differentiation of brain networks in a continuous manner and index the balance of integration and segregation. These techniques have thus increasingly complemented modular descriptions of brain networks, and offer a data-driven perspective on the gradual hierarchical organization of functional systems (Huntenburg et al., 2018; Margulies et al., 2016). A hierarchical perspective is furthermore supported by work showing a close association between functional gradients and main axes of microstructural differentiation in the cortex, which concomitantly describe a sensory-fugal pattern (Huntenburg et al., 2017; Paquola et al., 2019a, 2020). Connectome manifold learning has furthermore been applied to study healthy aging (Bethlehem et al., 2020; Lowe et al., 2019) and in the hierarchical organization of functional and structural networks in typical and atypical neurodevelopment (Hong et al., 2019; Paquola et al., 2019b; Park et al., 2020a, 2020b). In the context of BMI, these techniques have still not been applied but could promise to identify whether different patterns of functional network integration and segregation underpin inter-individual body mass variations.

As connectome manifold learning can generate cortical maps capturing large-scale principles of brain network organization and hierarchical differentiation, these features can be readily integrated with other aspects of brain organization. As such, spatial associations between connectome gradients and measures of brain morphology and microstructure can be calculated to query shared and unique effects. Furthermore, neural data that is not per se neuroimaging derived is increasingly represented in MRI reference space. One such repository are post-mortem gene expression maps disseminated by the Allen Institute for Brain Science (AIBS) (Arnatkeviciute et al., 2019; Chen et al., 2013; Dougherty et al., 2010; Gorgolewski et al., 2014, 2015; Hawrylycz et al., 2012; Kuleshov et al., 2016). This 
resource can inform spatial association analyses between imaging-derived findings and gene expression patterns. Coupled with gene enrichment analyses (Dougherty et al., 2010; Park et al., 2020a), these approaches can discover molecular, developmental, and disease related processes, and thus provide additional context for MRI-based findings. Recent studies capitalized on transcriptomic decoding to explore underpinnings of brain imaging findings in both healthy and diseased cohorts (Arnatkevičiūtè et al., 2019; Bertolero et al., 2019; Jahanshad et al., 2013; Paquola et al., 2019b; Park et al., 2020a; Thompson and Fransson, 2016).

Here, we studied associations between macroscale functional connectome organization and variations in BMI. Our functional network analysis was based on the identification of connectome manifolds, which offer a continuous and low dimensional analytical space to interrogate macroscale brain organization and network hierarchy (Burt et al., 2018; Fulcher et al., 2019; Vos de Wael et al., 2020). Capitalizing on the multimodal human connectome project (HCP) dataset (Van Essen et al., 2013; Glasser et al., 2013), we furthermore explored whether associations between functional manifolds and BMI existed above and beyond structural effects as measured by MRI-based measures of cortical thickness, sulco-gyral folding, and intracortical myelin. To explore neurobiological underpinnings of BMI-related whole-brain connectome changes, we performed spatial association analyses to postmortem gene expression data and carried out gene enrichment analyses.

\section{RESULTS}

We studied 325 young and healthy adults (mean \pm SD age $=28.56 \pm 3.74$ years; $55 \%$ female; mean $\pm \mathrm{SD} \mathrm{BMI}=26.30 \pm 5.16 \mathrm{~kg} / \mathrm{m}^{2}$, range $\left.16.65-47.76 \mathrm{~kg} / \mathrm{m}^{2}\right)$ from the $\mathrm{S} 900$ release of the HCP $(\operatorname{Van}$ Essen et al., 2013). See Methods for details on participant selection, image processing, and analysis. Reproducibility was studied in an additional 74 unrelated healthy adults from the HCP S1200 release $\left(\right.$ mean $\pm \mathrm{SD}$ age $=28.08 \pm 3.90$ years; $34 \%$ female; mean $\pm \mathrm{SD} \mathrm{BMI}=26.17 \pm 4.39 \mathrm{~kg} / \mathrm{m}^{2}$, range $18.89-39.47 \mathrm{~kg} / \mathrm{m}^{2}$ ), as well as an independent dataset of healthy adults acquired from the St. Vincent's Hospital (SVH; $\mathrm{n}=36$; mean $\pm \mathrm{SD}$ age $=38.78 \pm 10.52$ years; $47 \%$ female; mean $\pm \mathrm{SD}$ $\mathrm{BMI}=29.38 \pm 6.29 \mathrm{~kg} / \mathrm{m}^{2}$, range $23.15-57.13 \mathrm{~kg} / \mathrm{m}^{2}$ ).

\section{Macroscale functional manifolds and their association to BMI}

We constructed functional connectomes in individual subjects based on correlation analysis of resting-state functional MRI (rs-fMRI) data and estimated functional manifolds (Margulies et al., 2016) using a diffusion map embedding algorithm (Coifman and Lafon, 2006) implemented in the BrainSpace toolbox (https://github.com/MICA-MNI/BrainSpace; see Methods) (Vos de Wael et al., 2020). The template manifold was estimated using the group averaged functional connectome, and we aligned individual manifolds to this template using Procrustes rotations (Langs et al., 2015; Vos de Wael et al., 2020) . We selected three eigenvectors (M1, M2, M3), explaining approximately 48\% of variance in the template affinity matrix (Fig. 1A-B). Each eigenvector (also referred to as gradient) represents an axis of spatial variation in the functional connectome. In accordance to prior findings in the HCP dataset (Margulies et al., 2016; Vos de Wael et al., 2020), the eigenvectors differentiated primary sensory areas from higher order transmodal areas (M1), visual from somatomotor cortices (M2), and the multiple demand network from task negative systems (M3). 

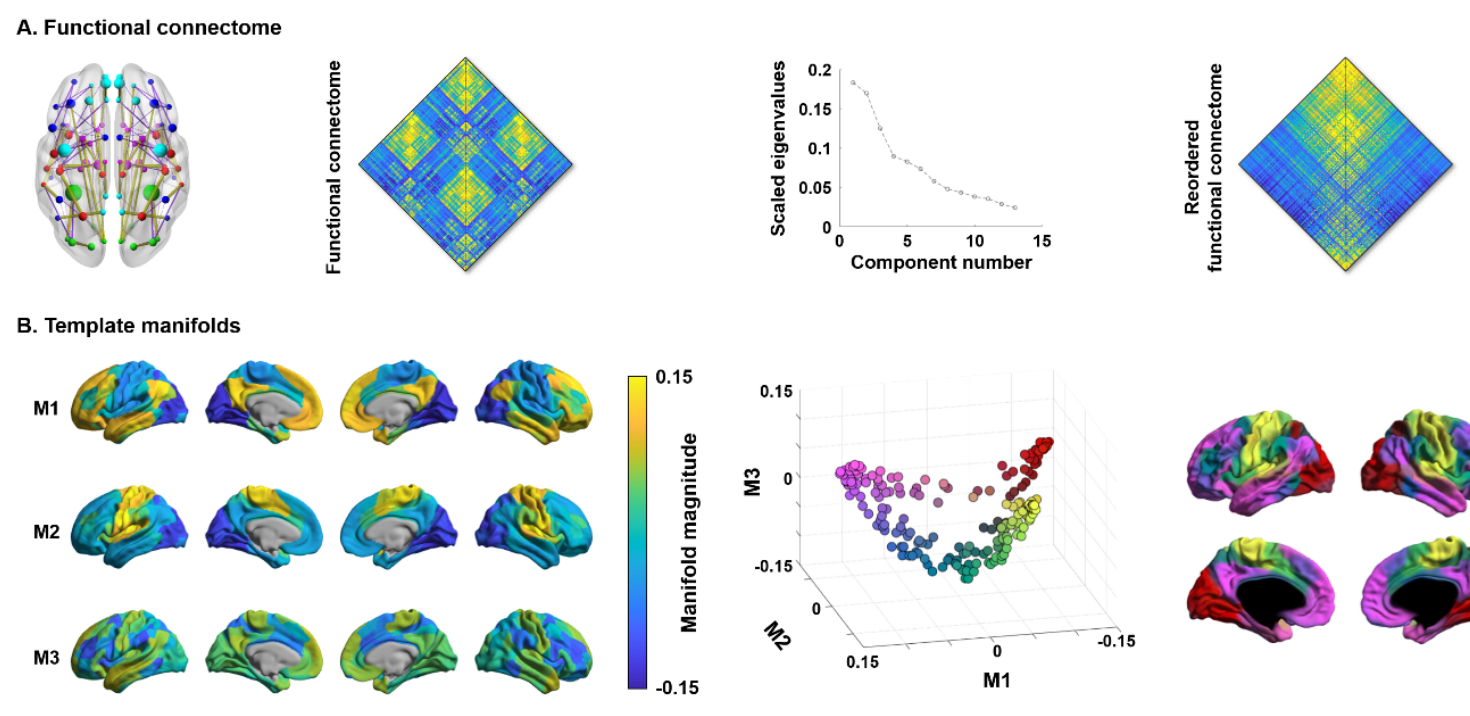

C. Functional connectome manifold associated with BMI
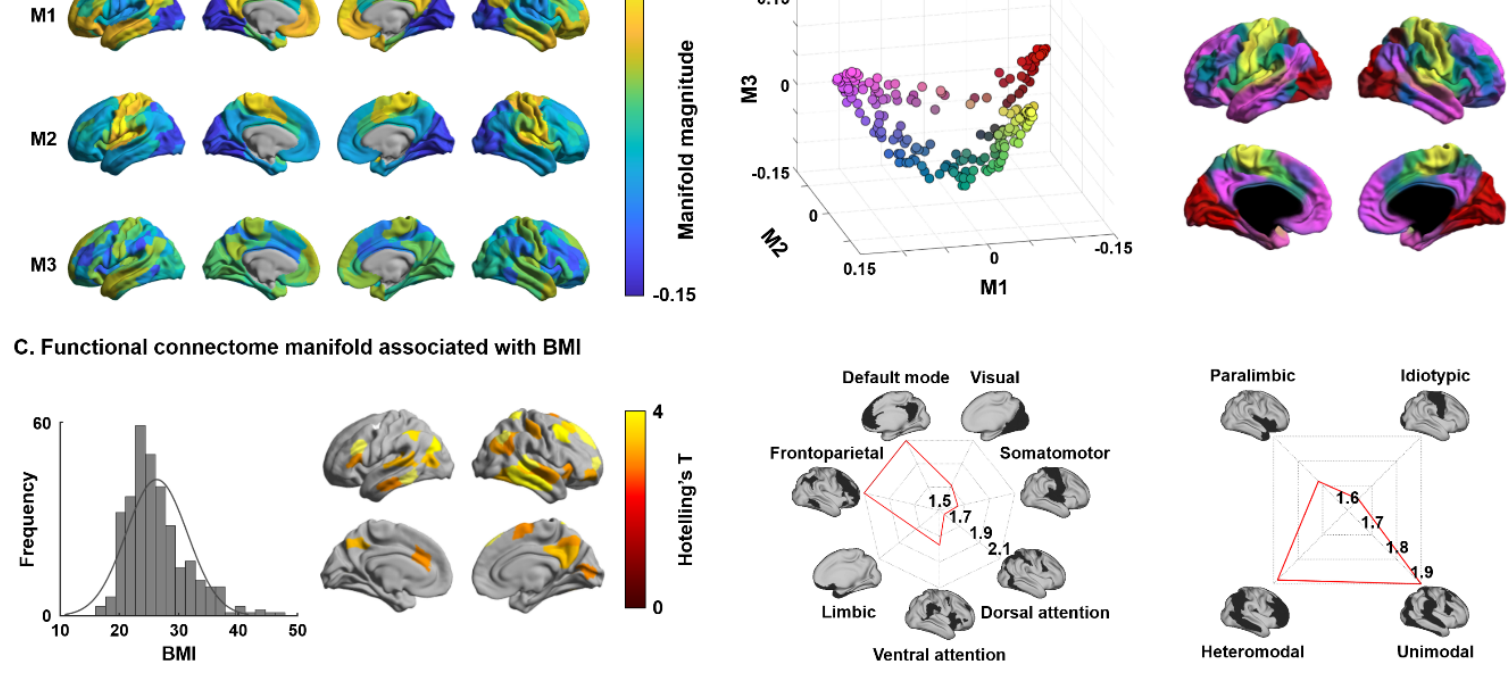

Fig. 1 | Functional connectome manifolds. (A) Functional connectivity schema, a group averaged functional connectome, and a scree plot describing connectome variance across functional components. The reordered functional connectivity matrix according to the first eigenvector (i.e., M1) is shown on the right side. (B) Template manifolds built by three dominant eigenvectors (M1, M2, M3) based on the group averaged functional connectome. The scatter plot represents each brain region projected onto the three-dimensional manifold space with different colors, also mapped to the cortical surface for visualization. (C) The distribution of BMI is reported on the left. Multivariate association between the three eigenvectors and BMI, highlighting regions showing significant associations to BMI. Findings were corrected for multiple comparisons using a false discovery rate $(\mathrm{FDR})<0.05$. Effects were stratified according to intrinsic functional communities (Yeo et al., 2011) and levels of cortical hierarchy (Mesulam, 1998) in the radar plots. Abbreviation: BMI, body mass index.

Multivariate analysis associated the three functional gradients with inter-individual differences in BMI, controlling for age and sex. Significant associations were identified in higher order transmodal areas (false discovery rate $(\mathrm{FDR})<0.05$; Fig. 1C). Stratifying effects according to intrinsic functional communities (Yeo et al., 2011) and the Mesulam model of cortical hierarchical laminar differentiation (Mesulam, 1998), we revealed highest effects in default mode and frontoparietal networks situated in both unimodal and heteromodal association cortices.

\section{Manifold eccentricity and body mass index}

To express the three-dimensional functional manifold structure through a single scalar, we computed the Euclidean distance between the center of template manifold and all data points (i.e., cortical regions) in manifold space (henceforth manifold eccentricity) for all participants (Fig. 2A). Linear correlations between BMI and functional manifold eccentricity of the regions identified from the multivariate association analysis confirmed significant associations $(r=0.16$ and $p<0.001$; nonparametric permutation tests; Fig. 2B). Correlations were repeated across different levels of cortical hierarchy intersected with significantly associated regions to BMI (see Fig. 1C), and strongest effects were identified in unimodal $(\mathrm{r}=0.19, \mathrm{p}<0.001)$ and heteromodal association areas $(\mathrm{r}=0.13, \mathrm{p}=$ 
0.011; Fig. 2C). Paralimbic areas showed marginal effects $(r=0.09, p=0.06)$. When analyzing correlations across intrinsic functional communities (Yeo et al., 2011), similar effects were identified with significant associations in default mode and frontoparietal networks as well as somatomotor and dorsal attention networks ( $p<0.05$; Fig. S1).

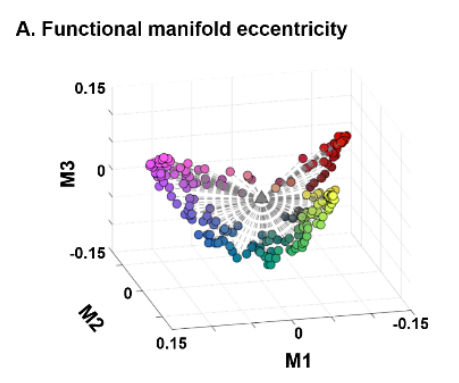

C. Correlation according to cortical hierarchy
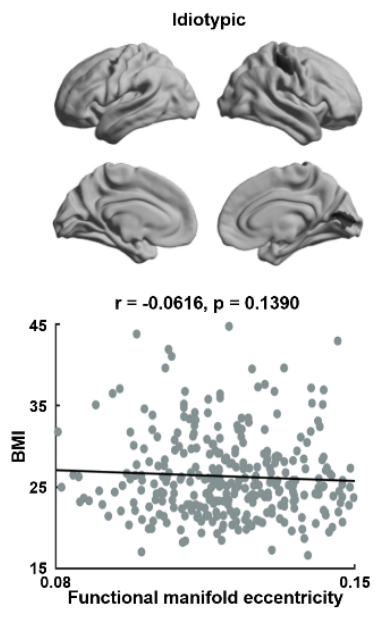
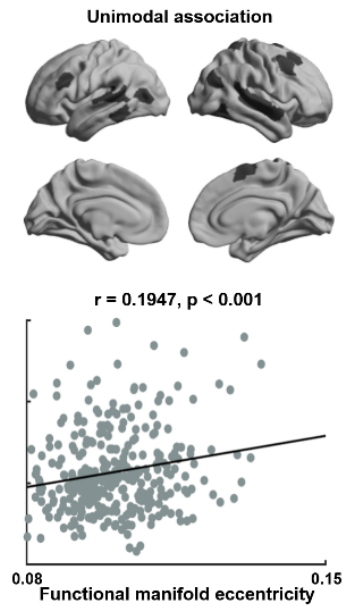
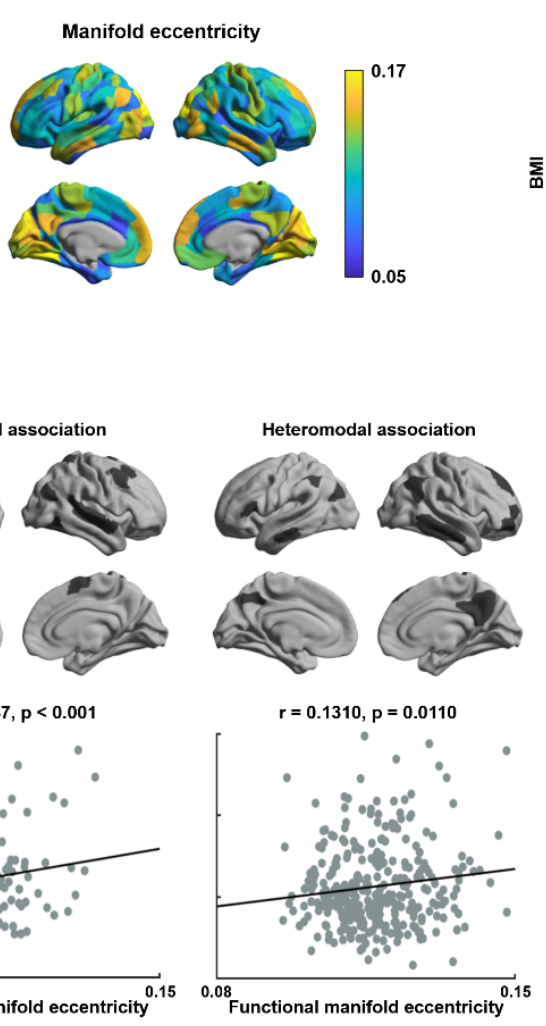
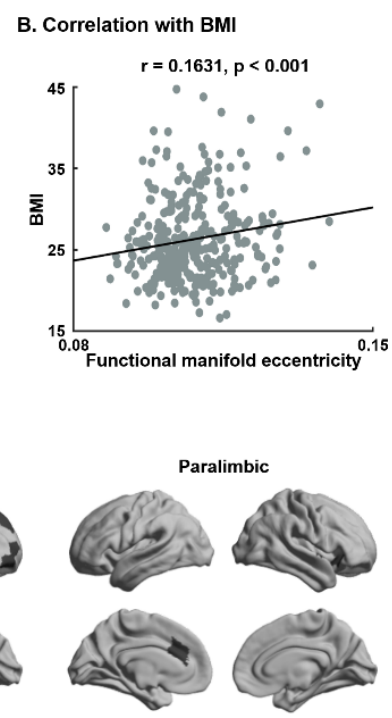

$r=0.0901, p=0.0600$

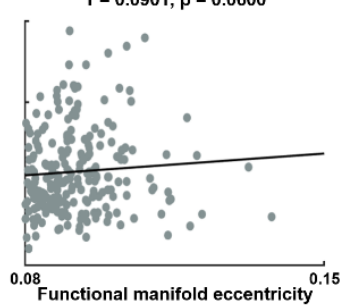

Fig. 2 | Association between BMI and functional manifold eccentricity. (A) Functional manifold eccentricity measured as the Euclidean distance between the center of the template manifold and each data point. (B) Linear correlation between BMI and manifold eccentricity. (C) Correlations according to a model of cortical hierarchy (Mesulam, 1998). Abbreviation: BMI, body mass index.

\section{Association between manifold eccentricity and modular measures}

To assess modular characteristics of BMI-related brain regions in terms of integration and segregation among different functional communities, we calculated within-module degree and participation coefficient (Power et al., 2013; Rubinov and Sporns, 2010) based on modules defined using an established intrinsic functional partitioning (Yeo et al., 2011) (Fig. 3A-B). We calculated linear correlation between manifold eccentricity and each modular measure in regions identified in the multivariate analysis (Fig. 3C). We found significant positive correlation between manifold eccentricity and within-module degree $(r=0.22, \mathrm{p}<0.001)$, while participation coefficient showed a negative association $(r=-0.16, p=0.004)$. These results indicate increased functional segregation of networks in individuals with higher BMI. Similar patterns were observed when defining modules using Louvain community detection algorithm (Blondel et al., 2008) or the Mesulam schema of cortical hierarchy and laminar differentiation (Mesulam, 1998) (Fig. S2). 

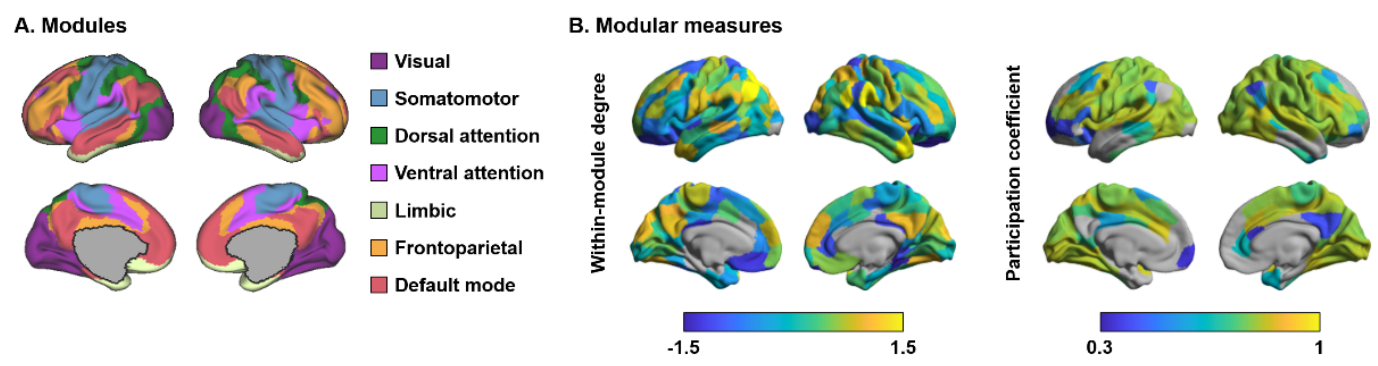

C. Association between manifold eccentricity and modular measures
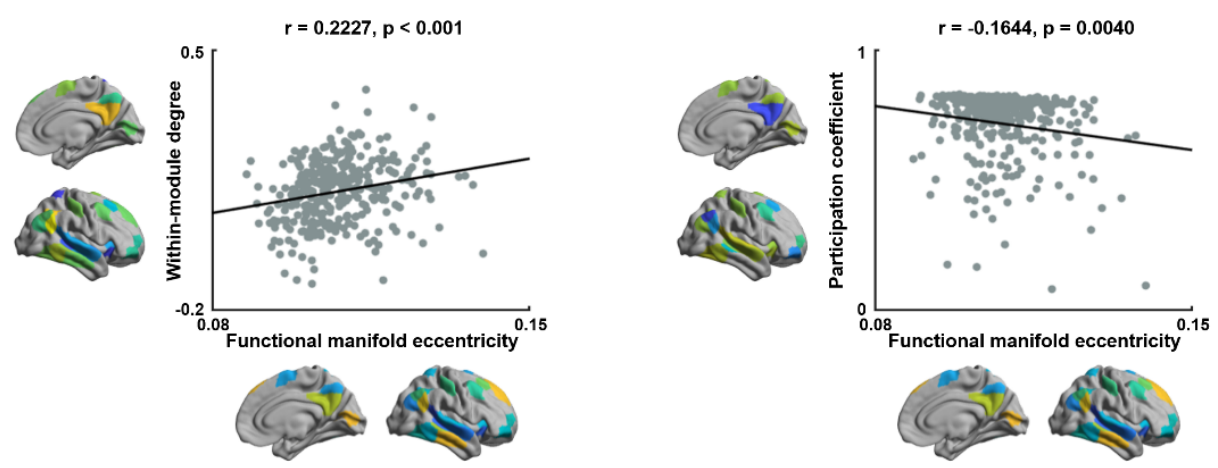

Fig. 3 | Manifold eccentricity and modular measures. (A) Functional communities based on intrinsic functional communities (Yeo et al., 2011). (B) Distribution of within-module degree and participation coefficient in the whole-brain. (C) Linear correlation between functional manifold eccentricity and modular measures in the identified regions from the multivariate analysis.

\section{Functional connectome manifold beyond brain structure}

Previous studies have reported associations between individual differences in BMI and MRI-based structural indices of cortical thickness, cortical folding, and tissue microstructure (Medic et al., 2016, 2019; Ronan et al., 2019; Vainik et al., 2018; Xu et al., 2013). Here, we explored whether functional connectome manifold findings were, in part, explainable by these underlying structural associations. To this end, we measured cortical morphology (cortical thickness and folding) and intracortical microstructure (the ratio between T1- and T2-weighted imaging contrast, a proxy for intracortical myelin) in the same subjects (Fig. 4A) (Glasser and Van Essen, 2011; Glasser et al., 2014; Paquola et al., 2019a). Two analyses were performed. First, we correlated BMI with these indices of brain structure, while controlling for age and sex. While cortical folding was not associated with BMI, a negative effect on cortical thickness was observed in the temporal pole (FDR $<0.05 ; \mathrm{r}=-0.21$ ), and we also found reductions in myelin proxies in occipital, central, and ventrolateral prefrontal regions with increases in BMI (FDR $<0.05 ; \mathrm{r}=-0.35$ ) (Fig. 4A and S3). Second, repeating the analysis associating BMI to manifold eccentricity after controlling for the measures of brain structure, findings were consistent in default mode and frontoparietal networks (Fig. 4B), while those in limbic networks slightly increased. Collectively, these findings suggest that functional associations were robust above and beyond associations between BMI and cortical (micro)structure. 
A. Different types of brain structure associated with BMI
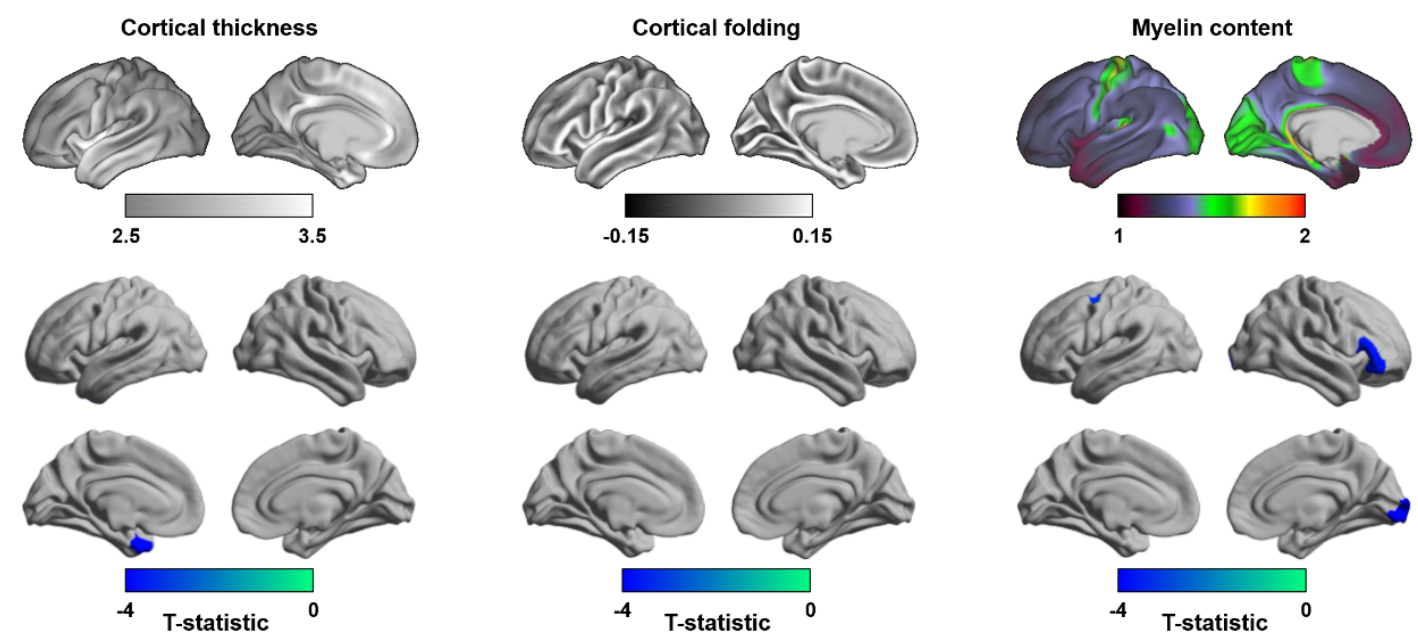

B. Functional connectome manifold associated with BMI after controlling for measures of brain structure
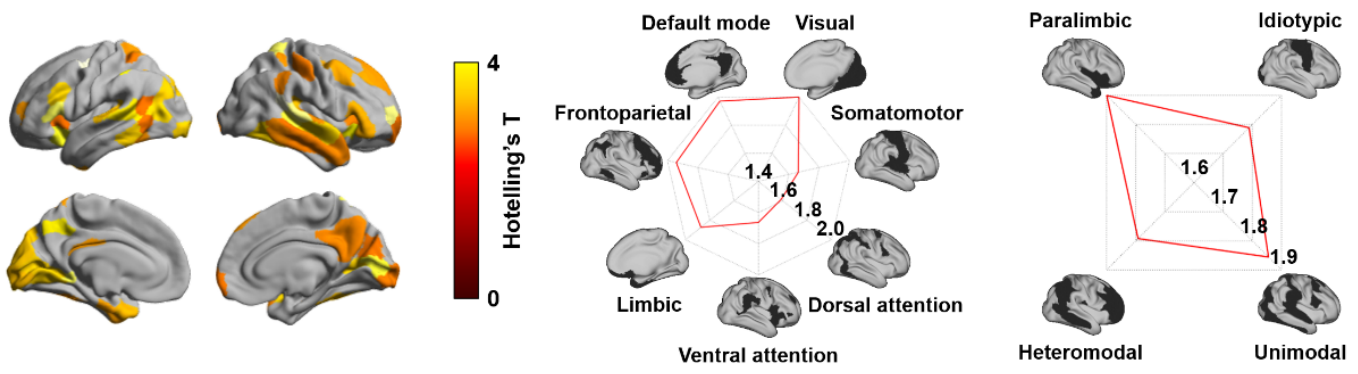

Fig. 4 | Effects of brain structures. (A) Measures of brain structure including cortical morphology and intracortical microstructure. (B) Multivariate association of the three manifolds with BMI after controlling for brain structures. Abbreviation: BMI, body mass index.

\section{Transcriptomic association analysis}

To provide neurobiological context to our macroscale findings (for details, see Methods), we correlated the spatial map of BMI-related functional manifold changes with cortical maps of postmortem gene expression data obtained from the AIBS (Gorgolewski et al., 2014, 2015; Hawrylycz et al., 2012). Among the significantly associated gene lists (FDR $<0.05$ ), only the genes consistently expressed across different donors (FDR < 0.05) (see Methods; Data S1) (Arnatkeviciute et al., 2019) were fed into the genome-wide association studies using Enrichr (https://amp.pharm.mssm.edu/Enrichr/) (Chen et al., 2013; Kuleshov et al., 2016). These findings pointed to strongest effects for genes previously shown to be associated to BMI (FDR $<0.05$; Fig. 5A). Further, cell-type specific expression analysis (http://genetics.wustl.edu/jdlab/csea-tool-2/) (Dougherty et al., 2010) suggested that genes associated with BMI-related functional manifold changes were enriched to cortical cells as well as those in striatum and cerebellum (FDR $<0.1$; Fig. 5B). Specifically, the genes are enriched to the excitatory and inhibitory cells of D1 medium spiny neurons in the striatum and stellate and basket cells in cerebellum, as well as in cortical neurons. These cells are known to indirectly regulate food-related reward processing and appetite (Durst et al., 2019; Matikainen-Ankney and Kravitz, 2018; Timper and Brüning, 2017; Vong et al., 2011). 

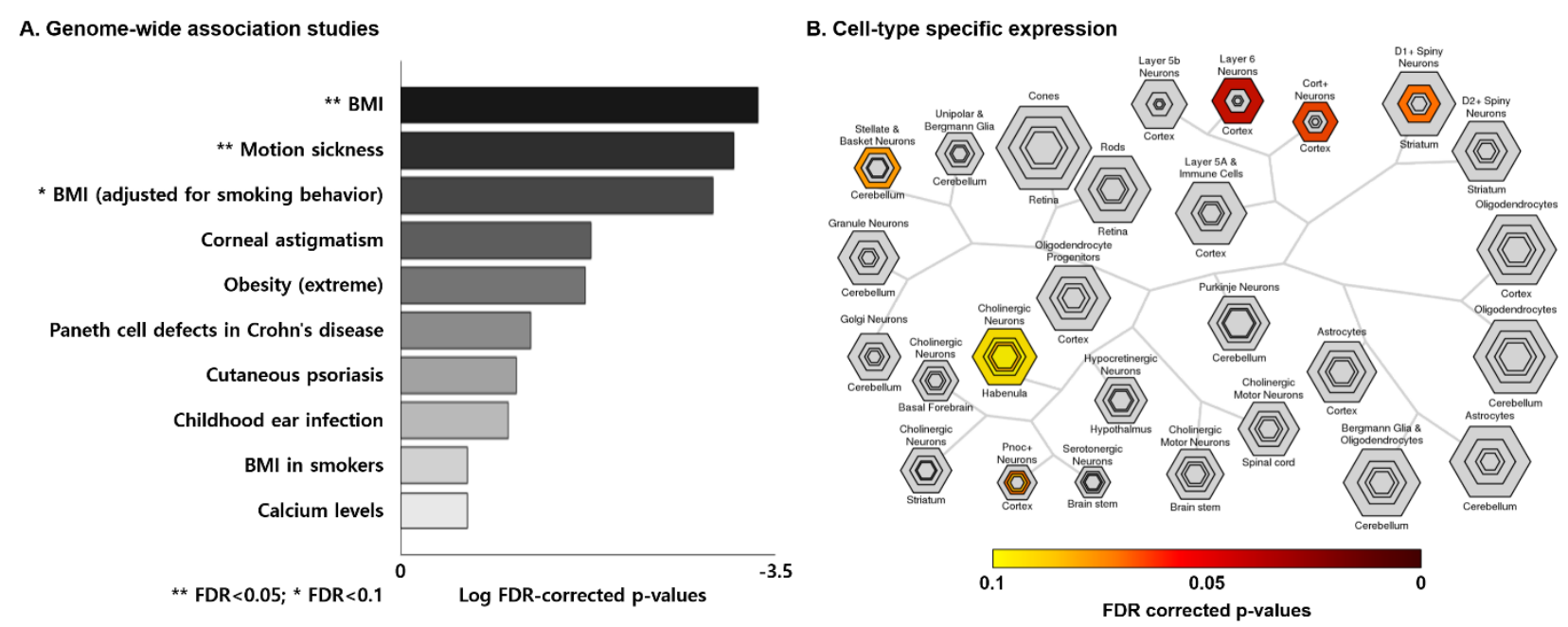

Fig. 5 | Transcriptomic analysis. (A) Top ten categories associated with gene expressions derived from genome-wide association studies. (B) Cell-type specific expression analysis identified candidate cell populations associated with genes expressed in the input spatial map (see Fig. 1C). Abbreviations: BMI, body mass index; FDR, false discovery rate.

\section{Sensitivity and replication experiments}

A series of analyses indicated the robustness of our findings.

a) Head motion effect. We repeated the multivariate analyses associating BMI to functional manifold data after controlling for head motion and observed similar spatial patterns (Fig. S4B).

b) Fluid intelligence and sleep quality effect. It has been shown that BMI also relates to fluid intelligence (Reed et al., 2010; Vainik et al., 2018) and sleep quality (Kohatsu et al., 2006; Vargas et al., 2014). This was also confirmed in this dataset, showing correlations between BMI and fluid intelligence $(r=-0.18, p=0.001)$ as well as quality of sleep $(r=0.13, p=0.03)$. We thus repeated the multivariate association analyses after additionally controlling for these factors. Findings were largely similar to our overall results (Fig. S4C).

c) Spatial scale. As the main analysis was performed using the Schaefer atlas with 200 parcels (Schaefer et al., 2018), we additionally evaluated the results at both coarser and finer parcellation schemes of 100,300 and 400 parcels, respectively. Findings were consistent across all parcel resolutions, despite subtle variations in the exact pattern of findings (Fig. S5, S6, and S7).

d) Matrix thresholding. While main findings were based on functional connectomes thresholded at a $10 \%$ density as in prior work (Hong et al., 2019; Margulies et al., 2016; Vos de Wael et al., 2020), we also repeated our analysis at 5\%,15\%, and 20\% densities (Fig. S8). We found highly similar patterns at these densities (mean spatial correlation across manifold maps, $\mathrm{r}=0.85$ ).

e) Group comparison. Instead of carrying out a correlation analysis between functional manifolds and BMI, we also performed a multivariate group comparison analysis to compare cortex-wide manifolds $(\mathrm{M} 1-\mathrm{M} 3)$ between individuals with healthy weight $(18.5 \leq \mathrm{BMI}<25)$ and those with non-healthy weight (BMI $\geq 25$ ). We observed virtually identical results to our main findings (Fig. S9A).

f) Multivariate association with weight. We additionally performed multivariate association analyses between weight and functional connectome manifolds with controlling for age and sex, as well as height. We found almost unchanged spatial patterns relative to our main findings (Fig. S9B).

g) Reproducibility in HCP validation dataset. We repeated the main analyses in an independent dataset from the HCP S1200 and found largely consistent results (Fig. S10).

h) Reproducibility in another dataset. Using an independent dataset with different acquisition parameters (see Methods), we replicated our main findings that the functional connectome manifolds in higher order brain networks are associated with BMI (Fig. S11). 


\section{DISCUSSION}

The human connectome is organized according to multiple processing hierarchies, which allow for integrative and segregated neural functions. Here, we assessed inter-individual differences in this architecture relative to phenotypic variations in body mass index (BMI), an important predictor of health, wellbeing, and life expectancy (Blüher, 2019; James, 2008; World Health Organization, 2020). Our approach leveraged recently established techniques that decompose the whole-brain functional connectome into a set of hierarchical gradients differentiating macroscale systems in a continuous manner along the cortical surface. We observed that unimodal and heteromodal association areas are more differentiated in individuals with higher BMI, suggestive of a potentially disrupted integration between different levels of macroscale hierarchy. Findings remained consistent when additionally controlling for variations in MRI-based measures of cortical morphology and microstructure, suggesting that functional network associations with BMI existed above and beyond regional effects on local brain structure. Functional connectome changes were found in cortical territories known to harbor genes previously implicated in BMI variations, as well as those involved in cortical, striatal, and cerebellar cells. These findings suggest functional network substrates of imbalances in BMI that may ultimately reflect macroscale effects of cellular-genetic associations to BMI.

Manifold learning techniques were utilized to compress and represent high dimensional functional connectomes along a series of spatial gradients. These approaches have recently seen an increasing adoption by the neuroimaging and network neuroscience communities (Burt et al., 2018; Demirtaş et al., 2019; Haak and Beckmann, 2020; Larivière et al., 2019b, 2019a; Müller et al., 2020; Paquola et al., 2019a, 2019b; Park et al., 2020a, 2020b; Vos de Wael et al., 2020; Vos De Wael et al., 2018) to interrogate macroscale neural organization and cortical hierarchy (Hong et al., 2019; Huntenburg et al., 2018; Margulies et al., 2016). Studying the HCP dataset, we identified three functional gradients explaining approximately $50 \%$ variance, in agreement with earlier studies in the same dataset (Margulies et al., 2016; Vos de Wael et al., 2020). Notably, associating inter-individual differences in BMI with manifold organization, we observed a marked increase in manifold eccentricity in individuals with higher BMI. These findings were predominantly observed in uni- and heteromodal association cortices that encompass integrative default mode and frontoparietal networks and are reflective of an increased differentiation of these areas to other brain networks. Prior fMRI studies reported atypical intrinsic functional connectivity in individuals with obesity, at both local node and global network levels, relative to individuals with a healthy weight (Chao et al., 2018; Chen et al., 2018; García-García et al., 2013, 2015; Park et al., 2016, 2018). Our findings complement these previous reports focusing on the analysis of connectivity patterns of specific areas (García-García et al., 2013, 2015; Lips et al., 2014; Park et al., 2015) alongside prior graph theoretical analyses (GarcíaGarcía et al., 2015; Park et al., 2016, 2018) in the context of person-to-person variations in BMI. Seed-based and graph theoretical functional connectivity studies found that individuals with obesity showed increased connectivity in nodes belonging to frontoparietal and default mode networks, relative to individuals with healthy weight (Chao et al., 2018; García-García et al., 2013, 2015). These findings are complemented by studies reporting positive associations between overall connectivity degree and broad variability in BMI, again with frequent findings in transmodal areas (Park et al., 2016, 2018). Longitudinal evidence also points to an association between BMI changes and connectivity of reward and frontoparietal networks, both when studying healthy individuals, without any interventions (Park et al., 2019a) and in work that administered repetitive transcranial magnetic stimulation targeting the dorsolateral prefrontal cortex (Kim et al., 2019). Beyond local connectivity, a more recent study reported an increased modular segregation in individuals with obesity compared 
to individuals with healthy weight, suggesting a shift of brain organization towards more lattice like functional networks as BMI increases (Ottino-González et al., 2020). A more segregated network organization has previously been reported in several psychiatric and neurological diseases, including attention deficit hyperactivity disorder (Cao et al., 2014, 2016, 2013; Liao et al., 2017; Wang et al., 2009), Alzheimer's disease (Bai et al., 2012; Dai and He, 2014; Liao et al., 2017; Zhao et al., 2012), as well as impulsivity (Davis et al., 2013). These studies noted that increased segregation may reduce global network efficiency and delay information transfer between nodes (Avena-Koenigsberger et al., 2014, 2018, 2019), potentially contributing to cognitive decline (Liao et al., 2017; Sporns, 2013). Based on these studies and our findings, the observed increased segregation of unimodal and heteromodal association cortices in individuals with high BMI could potentially reflect disruptions in feedforward and feedback processing, and potentially indicate atypical cognitive flexibility in individuals with high BMI (Martin et al., 2010; Moore et al., 2017; Moreno-Lopez et al., 2016; Morys et al., 2020; Park et al., 2016; Vainik et al., 2018; Val-Laillet et al., 2015; Whitmer et al., 2007; Ziauddeen et al., 2015). Of note, these findings were largely consistent when incorporating a range of potential confounds, including sleep quality as well as fluid intelligence. Moreover, we could observe similar patterns in an initially held out HCP subsample, as well as in a completely different dataset acquired in South Korea, supporting that our findings are overall robust.

In addition to conforming with established models of hierarchical network organization (Margulies et al., 2016; Mesulam, 1998), another appealing feature of the manifold framework is the ability to project connectome-derived findings back to cortical surfaces. In our analyses, this allowed for an integration of functional findings with morphological and microstructural measures in the same participants. Previous studies have explored morphological substrates of BMI variations, reporting cortical thinning in lateral prefrontal, entorhinal, and parahippocampal regions as BMI increases, indicating that overweight and obese people have reduced cortical thickness compared to people with a normal body weight (Medic et al., 2016; Ronan et al., 2019; Shaw et al., 2018; Vainik et al., 2018; Veit et al., 2014; Westwater et al., 2019). A recent multi-site study confirmed that high BMI ( $\geq 30)$ relates to reduced cortical thickness in temporal and frontal regions (Opel et al., 2020). In our study, we observed diffuse tendencies for decreased cortical thickness in individuals with higher BMI, with significant peak effects in temporopolar cortices. Findings were complemented by microstructural associations in primary sensory and ventrolateral prefrontal cortices, potentially indicative of myelin anomalies in individuals with high BMI that have already been suggested based on different methodologies (Metzler-Baddeley et al., 2018; Sena et al., 1985; Xiao et al., 2018). Notably, however, we observed virtually unchanged associations between BMI and functional connectome manifold changes when controlling for MRI-derived indices of morphology and microstructure, indicating that the functional connectome reorganization situated in higher order brain regions occurred above and beyond these underlying structural variations.

In addition to analyses of regional morphology and microstructure, we performed a transcriptomic association analysis based on post-mortem gene expression maps provided by the Allen Institute for Brain Sciences (AIBS). Although such transcriptomic associations were thus based on a different dataset, equivalent approaches have been increasingly adopted in neuroimaging research to identify potential molecular patterns that covary with macroscopic findings (Arnatkeviciute et al., 2019; Chen et al., 2013; Dougherty et al., 2010; Gorgolewski et al., 2015; Hawrylycz et al., 2012; Kuleshov et al., 2016). In our work, spatial association analyses pointed to specific gene sets, which we then decoded against findings from previously reported genome-wide association studies. This analysis demonstrated that the spatial pattern of functional connectome manifold changes co-localizes with 
genes previously implicated in BMI variations; as such, our enrichment analyses highlights that the macroscale functional connectome associations reported here likely reflect genetically mediated processes. Additional gene enrichment analyses furthermore suggested that the identified genes are mainly expressed by cortical neurons, together with cells in the cerebellum as well as D1 medium spiny neurons in the striatum. Although these associations are indirect and based on different samples, they may extend and recapitulate computational theories on circuit mechanisms contributing to BMI, and notably point to an atypical organization of dopaminergic circuits involving mesolimbic as well as cortical control systems.

In sum, the current study identified functional connectome substrates of BMI variations in healthy young adults based on advanced connectome manifold learning. Our findings point to a fractionation in the modular and hierarchical organization of the brain, specifically between unimodal and heteromodal association cortices. These findings were found to be robust across a range of confounds and baseline variations in cortical morphology, and could be replicated in two additional datasets. Further transcriptomic decoding showed that these patterns were associated with genetic factors contributing to BMI variations as well, and pointed to the expressions of cortical as well as subcortical neurons implicated in dopamine signaling. Our findings, thus, provide new insights into coupled macroscale and molecular underpinnings of BMI variations in the adult human brain.

\section{METHODS}

\section{Participants}

We obtained the minimally processed imaging and phenotypic data from the S900 release of HCP (Van Essen et al., 2013). We excluded participants who did not complete full imaging data (i.e., T1weighted, T2-weighted, and rs-fMRI) and who were genetically related (i.e., twin pairs), resulting in a total of 325 participants (mean \pm SD age $=28.56 \pm 3.74$ years; $55 \%$ female). The mean BMI of the participants was $26.30 \mathrm{~kg} / \mathrm{m}^{2}$ with SD of 5.16 , range $=16.65-47.76 \mathrm{~kg} / \mathrm{m}^{2}$ ), and the proportion of underweight $\left(\mathrm{BMI}<18.5 \mathrm{~kg} / \mathrm{m}^{2}\right)$, healthy weight $\left(18.5 \leq \mathrm{BMI}<25 \mathrm{~kg} / \mathrm{m}^{2}\right)$, overweight $(25 \leq \mathrm{BMI}<$ $30)$, and obesity (BMI $\geq 30)$ was 6:143:113:63. We additionally obtained data from the $\mathrm{S} 1200$ release of HCP to replicate our findings. The same exclusion criteria were applied. A total of 74 participants (mean $\pm \mathrm{SD}$ age $=28.08 \pm 3.90$ years; $34 \%$ female; mean $\pm \mathrm{SD}$ BMI $=26.17 \pm 4.39 \mathrm{~kg} / \mathrm{m}^{2}$, range $18.89-39.47 \mathrm{~kg} / \mathrm{m}^{2}$ ) were enrolled and the ratio of healthy weight, overweight, and obesity was 30:29:15. All MRI data used in this study were publicly available and anonymized. Participant recruitment procedures and informed consent forms, including consent to share de-identified data, were previously approved by the Washington University Institutional Review Board as part of the HCP.

To replicate findings, we collected an independent dataset from an independent site (St. Vincent's Hospital $(\mathrm{SVH}): \mathrm{n}=36$; mean $\pm \mathrm{SD}$ age $=38.78 \pm 10.52$ years; $47 \%$ female; mean $\pm \mathrm{SD}$ BMI $=29.38$ $\pm 6.29 \mathrm{~kg} / \mathrm{m}^{2}$, range $23.15-57.13 \mathrm{~kg} / \mathrm{m}^{2}$ ). Data collection and usage were approved from the Institutional Review Boards of the Catholic University of Korea (no. XC15DIMI0012, approved March 2015) and written and informed consent was obtained from all participants.

\section{MRI acquisition}

a) HCP: The HCP imaging data were scanned using a Siemens Skyra 3T at Washington University. The T1-weighted images were acquired using a magnetization-prepared rapid gradient echo (MPRAGE) sequence (repetition time $(\mathrm{TR})=2,400 \mathrm{~ms}$; echo time $(\mathrm{TE})=2.14 \mathrm{~ms}$; field of view $(\mathrm{FOV})=224 \times 224 \mathrm{~mm}^{2}$; voxel size $=0.7 \mathrm{~mm}^{3}$; and number of slices $=256$ ). The T2-SPACE sequence 
bioRxiv preprint doi: https://doi.org/10.1101/2020.08.07.241794; this version posted August 7, 2020. The copyright holder for this preprint (which was not certified by peer review) is the author/funder, who has granted bioRxiv a license to display the preprint in perpetuity. It is made available under aCC-BY-ND 4.0 International license.

was used for scanning T2-weighted structural data, and the acquisition parameters were the same as the T1-weighted data except for the TR $(3,200 \mathrm{~ms})$ and TE $(565 \mathrm{~ms})$. The rs-fMRI data were collected using a gradient-echo EPI sequence $\left(\mathrm{TR}=720 \mathrm{~ms}\right.$; TE $=33.1 \mathrm{~ms} ; \mathrm{FOV}=208 \times 180 \mathrm{~mm}^{2}$; voxel size $=2 \mathrm{~mm}^{3}$; number of slices $=72$; and number of volumes $=1,200$ ). During the rs-fMRI scan, participants were instructed to keep their eyes open looking at a fixation cross. Two sessions of rsfMRI data were acquired; each of them contained data of left-to-right and right-to-left phase-encoded directions, providing up to four time series per participant.

b) SVH: The SVH imaging data were scanned using a Siemens Magnetom 3T scanner equipped with a 32-channel head coil. The T1-weighted images were acquired using a MPRAGE sequence $(\mathrm{TR}=$ $1,900 \mathrm{~ms} ; \mathrm{TE}=2.49 \mathrm{~ms} ; \mathrm{FOV}=250 \times 250 \mathrm{~mm}^{2} ;$ voxel size $=1 \mathrm{~mm}^{3}$; and number of slices $\left.=160\right)$. The rs-fMRI data were collected using a gradient-echo EPI sequence $(\mathrm{TR}=2,490 \mathrm{~ms}$; TE $=30 \mathrm{~ms}$; $\mathrm{FOV}=220 \times 220 \mathrm{~mm}^{2}$; voxel size $=3.4 \times 3.4 \times 3 \mathrm{~mm}^{3}$; number of slices $=36$; and number of volumes $=150)$.

\section{Data preprocessing}

a) HCP: HCP data were minimally preprocessed using FSL, FreeSurfer, and Workbench (Fischl, 2012; Glasser et al., 2013; Jenkinson et al., 2012). Structural MRI data were corrected for gradient nonlinearity and b0 distortions, and co-registration was performed between the T1- and T2-weighted data using a rigid-body transformation. Bias field was adjusted using the inverse intensities from the T1- and T2-weighting. Processed data were nonlinearly registered to MNI152 space, and white and pial surfaces were generated by following the boundaries between different tissues (Dale et al., 1999; Fischl et al., 1999a, 1999b). The midthickness surface was generated by averaging white and pial surfaces, and it was used to generate the inflated surface. The spherical surface was registered to the Conte69 template with 164k vertices (Van Essen et al., 2012) using MSMAll (Glasser et al., 2016) and downsampled to a $32 \mathrm{k}$ vertex mesh. The rs-fMRI data were preprocessed as follows: First, EPI distortions and head motion were corrected, and data were registered to the T1-weighted data and subsequently to MNI152 space. Magnetic field bias correction, skull removal, and intensity normalization were performed. Noise components attributed to head movement, white matter, cardiac pulsation, arterial, and large vein related contributions were removed using FMRIB's ICA-based Xnoiseifier (ICA-FIX) (Salimi-Khorshidi et al., 2014). Preprocessed time series were mapped to the standard grayordinate space, with a cortical ribbon-constrained volume-to-surface mapping algorithm. The total mean of the time series of each left-to-right/right-to-left phase-encoded data was subtracted to adjust the discontinuity between the two datasets and they were concatenated to form a single time series data.

b) SVH: SVH data were processed using the fusion of the neuroimaging preprocessing (FuNP) pipeline integrating AFNI, FreeSurfer, FSL, and ANTs (Avants et al., 2011; Cox, 1996; Fischl, 2012; Glasser et al., 2013; Jenkinson et al., 2012; Park et al., 2019b). T1-weighted data were processed using the equivalent procedures as in HCP data. The rs-fMRI preprocessing involved removal of the first $10 \mathrm{~s}$ ( 5 volumes) to allow for magnetic field saturation. Head motion and slice timing were corrected, and volumes with frame-wise displacement $>0.5 \mathrm{~mm}$ were removed. After removing nonbrain tissues, intensity was normalized. Nuisance variables of head motion, white matter, cerebrospinal fluid, cardiac pulsation, and arterial and large vein related contributions were removed using ICA-FIX (Salimi-Khorshidi et al., 2014). Registration from fMRI onto the T1-weighted data and subsequently onto the MNI $3 \mathrm{~mm}^{3}$ standard space was performed. Data underwent a band-pass filter with a pass band from 0.009 and $0.08 \mathrm{~Hz}$ and spatial smoothing with a full width at half maximum of $5 \mathrm{~mm}$. The processed fMRI data were mapped to the cortical surface with a cortical ribbon-constrained volume-to-surface mapping algorithm. 
bioRxiv preprint doi: https://doi.org/10.1101/2020.08.07.241794; this version posted August $7,2020$. The copyright holder for this preprint (which was not certified by peer review) is the author/funder, who has granted bioRxiv a license to display the preprint in perpetuity. It is made available under aCC-BY-ND 4.0 International license.

Park et al. | Functional connectome substrates of BMI variations

\section{Low dimensional functional manifold identification}

We generated functional connectomes by computing linear correlations of the time series between two different brain regions, using the Schaefer 7-network based atlas with 200 parcels (Schaefer et al., 2018). Correlation coefficients underwent Fisher's r-to-z transformations to render data more normally distributed (Thompson and Fransson, 2016). Cortex-wide functional manifolds (i.e., the principal eigenvectors explaining spatial shifts in the functional connectome) were estimated using BrainSpace (https://github.com/MICA-MNI/BrainSpace) (Vos de Wael et al., 2020). First, a template manifold was estimated from a group average functional connectome (Fig. 1A). A similarity matrix, capturing similarity of connections among different brain regions, was constructed using a normalized angle kernel with a connection density of $10 \%$. We generated the connectome manifolds (Fig. 1B) using diffusion map embedding (Coifman and Lafon, 2006), which is robust to noise and computationally efficient compared to other non-linear manifold learning techniques (Von Luxburg, 2007; Tenenbaum et al., 2000). It is controlled by two parameters $\alpha$ and t, where $\alpha$ controls the influence of the density of sampling points on the manifold ( $\alpha=0$, maximal influence; $\alpha=1$, no influence) and t scales eigenvalues of the diffusion operator. As in prior applications (Hong et al., 2019; Margulies et al., 2016; Paquola et al., 2019a; Vos de Wael et al., 2020), we set $\alpha=0.5$ and $t=$ 0 to retain the global relations between data points in the embedded space. In this new manifold, interconnected brain regions are closely located, and the regions with weak inter-connectivity located farther apart. The individual-level manifolds were estimated and aligned to the template manifold via Procrustes alignment (Langs et al., 2015; Vos de Wael et al., 2020).

\section{Macroscale connectome associated with body mass index}

We performed multivariate association analysis between BMI and the first three functional manifolds, which explained approximately $50 \%$ in connectome variance, with the model controlling for age and sex. We corrected for multiple comparisons using the FDR procedure (Benjamini and Hochberg, 1995). We summarized multivariate association statistics within well-established resting-state functional communities (Yeo et al., 2011) and with respect to proposed levels of cortical hierarchy (Mesulam, 1998) (Fig. 1C). We simplified the multivariate manifolds into a single scalar value by calculating the Euclidean distance between the center of template manifold and all data points (i.e., brain regions) in the manifold space for each individual, which was referred to as manifold eccentricity (Fig. 2A) (Bethlehem et al., 2020; Park et al., 2020b). We calculated linear correlation between BMI and the manifold eccentricity of the identified regions derived from the multivariate analysis (Fig. 2B). We also stratified associations according to four cortical hierarchy levels (Fig. 2C) (Mesulam, 1998) and seven functional communities (Fig. S1) (Yeo et al., 2011). The significance of the correlation was assessed using 1,000 permutation tests by randomly shuffling participants. A null distribution was constructed and the real correlation strength was deemed significant if it did not belong to the $95 \%$ of the distribution (two-tailed $\mathrm{p}<0.05$ ).

\section{Modular characteristic according to the functional manifold eccentricity}

To assess how the modular architecture changes according to the functional connectome manifolds, we calculated Pearson's correlation between the manifold eccentricity and within-module degree and participation coefficient (Power et al., 2013; Rubinov and Sporns, 2010) in regions identified by the multivariate analysis (Fig. 3 and S2). Modules were defined using established intrinsic functional communities (Yeo et al., 2011), a Louvain community detection algorithm (Blondel et al., 2008), and a schema of cortical hierarchy (Mesulam, 1998). Within-module degree is the degree centrality within a module, indicating the intra-modular connections, while participation coefficient represents intermodular connections (Power et al., 2013; Rubinov and Sporns, 2010). In other words, high withinmodule degree represents that a given node has the property of being a hub node within a given module. In contrast, high participation coefficient indicates the node has edges distributed equally to 
bioRxiv preprint doi: https://doi.org/10.1101/2020.08.07.241794; this version posted August $7,2020$. The copyright holder for this preprint (which was not certified by peer review) is the author/funder, who has granted bioRxiv a license to display the preprint in perpetuity. It is made available under aCC-BY-ND 4.0 International license.

Park et al. | Functional connectome substrates of BMI variations

other modules. The significance of the associations between manifold eccentricity and modular measures were assessed using 1,000 permutation tests by randomly shuffling subjects.

\section{Associations to brain structure}

To assess morphological and microstructural underpinnings (Fig. 4A), we first correlated BMI with MRI-based measures of cortical morphology, i.e., cortical thickness and cortical folding, and in vivo proxies of intracortical microstructure, i.e., the ratio of the T1-weighted and T2-weighted imaging contrast in voxels between the white and pial surfaces (Glasser and Van Essen, 2011; Glasser et al., 2014; Paquola et al., 2019a). We also repeated the association analysis between BMI and manifold changes, after controlling for regional structural indices (Fig. 4B).

\section{$\underline{\text { Transcriptomic association analysis }}$}

Transcriptomic association analysis explored neurobiological underpinnings of functional manifold eccentricity (Fig. 5) (Arnatkeviciute et al., 2019; Chen et al., 2013; Dougherty et al., 2010; Gorgolewski et al., 2015; Hawrylycz et al., 2012; Kuleshov et al., 2016). Specifically, we correlated the t-statistical map of manifold changes associated with BMI with post-mortem gene expression map from the AIBS using the Neurovault gene decoding tool (Gorgolewski et al., 2015; Hawrylycz et al., 2012). Neurovault implements mixed-effect analysis to estimate associations between the input tstatistic map and the genes of AIBS donor brains yielding the gene symbols associated with the input $\mathrm{t}$-statistic map. Gene symbols that passed a significance level of FDR-corrected $\mathrm{p}<0.05$ were further tested whether they are consistently expressed across donors using abagen (https://github.com/rmarkello/abagen) (Arnatkeviciute et al., 2019). For each gene, we estimated the whole-brain expression map for each donor, and correlated the maps between all pairs of donors. Genes showing consistent a whole-brain expression pattern across donors (FDR $<0.05$ ) were compared with genes extracted from genome-wide association studies using Enrichr (https://amp.pharm.mssm.edu/Enrichr/) (Chen et al., 2013; Kuleshov et al., 2016). Then we fed the consistent genes into the cell-type specific expression analysis (http://genetics.wustl.edu/jdlab/cseatool-2/) to identify candidate cell populations likely to be associated with input gene lists (Dougherty et al., 2010). Significances were assessed using a z-score modification of Fisher's exact test and FDR correction.

\section{Sensitivity and reproducibility analyses}

a) Head motion effect. To assess the effects of head motion on functional connectome manifolds, we repeated multivariate association analysis with controlling for age and sex, as well as head motion that calculated based on the frame-wise displacement during fMRI scan (Fig. S4B).

b) Fluid intelligence and sleep quality effect. It is known that BMI is related to fluid intelligence (Reed et al., 2010; Vainik et al., 2018) and sleep quality (Kohatsu et al., 2006; Vargas et al., 2014). To assess the relationship between BMI and these factors, we obtained fluid intelligence score measured using Penn Progressive Matrices (Bilker et al., 2012) and quality of sleep measured using Pittsburgh Sleep Quality Index (Backhaus et al., 2002; Buysse et al., 1989; Carpenter and Andrykowski, 1998). We repeated multivariate analyses to associate functional connectome manifolds and BMI with controlling for age and sex, as well as fluid intelligence and sleep quality (Fig. S4C).

c) Spatial scale. To evaluate the impact of spatial scale, we repeated our analyses across different scales of the Schaefer atlas (i.e., 100, 300, or 400 regions) (Fig. S5, S6, and S7) (Schaefer et al., 2018).

d) Matrix thresholding. We repeated functional manifold estimation using functional connectomes with different levels of density from 5\% to $20 \%$ with an interval of 5\% (Fig. S8). 
e) Group comparison. We compared functional connectome manifolds spanned by M1-M3 between individuals with healthy weight $(18.5 \leq \mathrm{BMI}<25)$ and non-healthy weight $(\mathrm{BMI} \geq 25)$, controlling for age and sex, to assess whether the findings from multivariate association to BMI are similar to those from multivariate group comparison $($ Fig. S9A). The six underweight $($ BMI $<18.5)$ individuals were excluded.

f) Multivariate association with weight. We performed multivariate analyses to associate functional connectome manifolds with weight after controlling for age, sex, and height to additionally validate our main findings (Fig. S9B).

g) Reproducibility in HCP validation dataset. We performed the same analyses using the validation dataset obtained from the S1200 release of the HCP to replicate our findings $(n=74)$ (Fig. S10).

h) Reproducibility in another dataset. We replicated our findings using the independent SVH dataset $(\mathrm{n}=36)$ (Fig. S11). 
bioRxiv preprint doi: https://doi.org/10.1101/2020.08.07.241794; this version posted August 7 2020. The copyright holder for this preprint (which was not certified by peer review) is the author/funder, who has granted bioRxiv a license to display the preprint in perpetuity. It is made available under aCC-BY-ND 4.0 International license.

Park et al. | Functional connectome substrates of BMI variations

\section{ACKNOWLEDGMENTS}

Data were provided, in part, by the Human Connectome Project, WU-Minn Consortium (Principal Investigators: David Van Essen and Kamil Ugurbil; 1U54MH091657) funded by the 16 NIH Institutes and Centers that support the NIH Blueprint for Neuroscience Research, and by the McDonnell Center for Systems Neuroscience at Washington University. Dr Bo-yong Park was funded by Molson NeuroEngineering fellowship by Montreal Neurological Institute and Hospital (MNI) and the Fonds de la Recherche due Québec - Santé (FRQ-S). Drs Bo-yong Park and Boris C. Bernhardt are jointly funded through an MNI-Cambridge collaborative award. Dr Boris Bernhardt further acknowledges research support from the National Science and Engineering Research Council of Canada (NSERC Discovery1304413), the Canadian Institutes of Health Research (CIHR FDN-154298), SickKids Foundation (NI17-039), Azrieli Center for Autism Research (ACAR-TACC), and the Tier-2 Canada Research Chairs program.

\section{Author contributions}

B.P. and B.C.B. designed the experiments, analyzed the data, and wrote the manuscript. H.P., K.B., H.L., and S.H.K. aided the experiments. H.P., F.M., M.K., S.V., and A.D. reviewed the manuscript. B.P. and B.C.B. are the corresponding authors of this work and have responsibility for the integrity of the data analysis.

\section{Conflict of interest}

The authors declare no conflicts of interest. 
bioRxiv preprint doi: https://doi.org/10.1101/2020.08.07.241794; this version posted August $7,2020$. The copyright holder for this preprint (which was not certified by peer review) is the author/funder, who has granted bioRxiv a license to display the preprint in perpetuity. It is made available under aCC-BY-ND 4.0 International license.

Park et al. | Functional connectome substrates of BMI variations

\section{References}

Arnatkeviciute, A., Fulcher, B.D., and Fornito, A. (2019). A practical guide to linking brain-wide gene expression and neuroimaging data. Neuroimage 189, 353-367.

Arnatkevičiūtè, A., Fulcher, B.D., and Fornito, A. (2019). Uncovering the transcriptional correlates of hub connectivity in neural networks. Front. Neural Circuits 13, 47.

Avants, B.B., Tustison, N.J., Song, G., Cook, P.A., Klein, A., and Gee, J.C. (2011). A reproducible evaluation of ANTs similarity metric performance in brain image registration. Neuroimage 54, 2033-2044.

Avena-Koenigsberger, A., Goñi, J., Betzel, R.F., van den Heuvel, M.P., Griffa, A., Hagmann, P., Thiran, J.P., and Sporns, O. (2014). Using Pareto optimality to explore the topology and dynamics of the human connectome. Philos. Trans. R. Soc. B Biol. Sci. 369.

Avena-Koenigsberger, A., Misic, B., and Sporns, O. (2018). Communication dynamics in complex brain networks. Nat. Rev. Neurosci. 19, 17-33.

Avena-Koenigsberger, A., Yan, X., Kolchinsky, A., Van Den Heuvel, M.P., Hagmann, P., and Sporns, O. (2019). A spectrum of routing strategies for brain networks. PLoS Comput. Biol. 15, 124.

Backhaus, J., Junghanns, K., Broocks, A., Riemann, D., and Hohagen, F. (2002). Test-retest reliability and validity of the Pittsburgh Sleep Quality Index in primary insomnia. J. Psychosom. Res. 53, 737-740.

Bai, F., Shu, N., Yuan, Y., Shi, Y., Yu, H., Wu, D., Wang, J., Xia, M., He, Y., and Zhang, Z. (2012). Topologically convergent and divergent structural connectivity patterns between patients with remitted geriatric depression and amnestic mild cognitive impairment. J. Neurosci. 32, 43074318.

Benjamini, Y., and Hochberg, Y. (1995). Controlling the False Discovery Rate : A Practical and Powerful Approach to Multiple Testing. J. R. Stat. Soc. 57, 289-300.

Bertolero, M.A., Blevins, A.S., Baum, G.L., Gur, R.C., Gur, R.E., Roalf, D.R., Satterthwaite, T.D., and Bassett, D.S. (2019). The human brain's network architecture is genetically encoded by modular pleiotropy. BioRxiv.

Bethlehem, R.A.I., Paquola, C., Seidlitz, J., Ronan, L., Bernhardt, B., Consortium, C.-C., and Tsvetanov, K.A. (2020). Dispersion of functional gradients across the lifespan. BioRxiv.

Bilker, W.B., Hansen, J.A., Brensinger, C.M., Richard, J., Gur, R.E., and Gur, R.C. (2012). Development of Abbreviated Nine-Item Forms of the Raven's Standard Progressive Matrices Test. Assessment 19, 354-369.

Blondel, V.D., Guillaume, J.L., Lambiotte, R., and Lefebvre, E. (2008). Fast unfolding of communities in large networks. J. Stat. Mech. Theory Exp. 2008.

Blüher, M. (2019). Obesity: global epidemiology and pathogenesis. Nat. Rev. Endocrinol. 15, 288298.

Brooks, S.J., Cedernaes, J., and Schiöth, H.B. (2013). Increased prefrontal and parahippocampal activation with reduced dorsolateral prefrontal and insular cortex activation to food images in obesity: a meta-analysis of fMRI studies. PLoS One 8, 1-9. 
Burt, J.B., Demirtaş, M., Eckner, W.J., Navejar, N.M., Ji, J.L., Martin, W.J., Bernacchia, A., Anticevic, A., and Murray, J.D. (2018). Hierarchy of transcriptomic specialization across human cortex captured by structural neuroimaging topography. Nat. Neurosci. 21, 1251-1259.

Buysse, D.J., Reynolds, C.F., Monk, T.H., Berman, S.R., and Kupfer, D.J. (1989). The Pittsburgh sleep quality index: A new instrument for psychiatric practice and research. Psychiatry Res. 28, 193-213.

Cao, M., Shu, N., Cao, Q., Wang, Y., and He, Y. (2014). Imaging Functional and Structural Brain Connectomics in Attention-Deficit/Hyperactivity Disorder. Mol. Neurobiol. 50, 1111-1123.

Cao, M., Huang, H., Peng, Y., Dong, Q., and He, Y. (2016). Toward Developmental Connectomics of the Human Brain. Front. Neuroanat. 10, 25.

Cao, Q., Shu, N., An, L., Wang, P., Sun, L., Xia, M.R., Wang, J.H., Gong, G.L., Zang, Y.F., Wang, Y.F., et al. (2013). Probabilistic diffusion tractography and graph theory analysis reveal abnormal white matter structural connectivity networks in drug-naive boys with attention deficit/hyperactivity disorder. J. Neurosci. 33, 10676-10687.

Carpenter, J.S., and Andrykowski, M.A. (1998). Psychometric evaluation of the Pittsburgh Sleep Quality Index. J. Psychosom. Res. 45, 5-13.

Chao, S.H., Liao, Y.T., Chen, V.C.H., Li, C.J., McIntyre, R.S., Lee, Y., and Weng, J.C. (2018). Correlation between brain circuit segregation and obesity. Behav. Brain Res. 337, 218-227.

Chen, E.Y., Tan, C.M., Kou, Y., Duan, Q., Wang, Z., Meirelles, G.V., Clark, N.R., and Ma'ayan, A. (2013). Enrichr: interactive and collaborative HTML5 gene list enrichment analysis tool. BMC Bioinformatics 14, 128.

Chen, V.C.-H., Liu, Y.-C., Chao, S.-H., McIntyre, R.S., Cha, D.S., Lee, Y., and Weng, J.-C. (2018). Brain structural networks and connectomes: the brain\&ndash;obesity interface and its impact on mental health. Neuropsychiatr. Dis. Treat. 14, 3199-3208.

Coifman, R.R., and Lafon, S. (2006). Diffusion maps. Appl. Comput. Harmon. Anal. 21, 5-30.

Cox, R.W. (1996). AFNI : Software for Analysis and Visualization of Functional Magnetic Resonance Neuroimages. Comput. Biomed. Res. 29, 162-173.

Dai, Z., and He, Y. (2014). Disrupted structural and functional brain connectomes in mild cognitive impairment and Alzheimer's disease. Neurosci. Bull. 30, 217-232.

Dale, A.M., Fischl, B., and Sereno, M.I. (1999). Cortical surface-based analysis: I. Segmentation and surface reconstruction. Neuroimage 9, 179-194.

Davis, F.C., Knodt, A.R., Sporns, O., Lahey, B.B., Zald, D.H., Brigidi, B.D., and Hariri, A.R. (2013). Impulsivity and the modular organization of resting-state neural networks. Cereb. Cortex $23,1444-1452$.

Demirtaş, M., Burt, J.B., Helmer, M., Ji, J.L., Adkinson, B.D., Glasser, M.F., Van Essen, D.C., Sotiropoulos, S.N., Anticevic, A., and Murray, J.D. (2019). Hierarchical Heterogeneity across Human Cortex Shapes Large-Scale Neural Dynamics. Neuron 101, 1181-1194.

Dougherty, J.D., Schmidt, E.F., Nakajima, M., and Heintz, N. (2010). Analytical approaches to RNA profiling data for the identification of genes enriched in specific cells. Nucleic Acids Res. 38, 4218-4230.

Durst, M., Könczöl, K., Balázsa, T., Eyre, M.D., and Tóth, Z.E. (2019). Reward-representing D1- 
bioRxiv preprint doi: https://doi.org/10.1101/2020.08.07.241794; this version posted August 7, 2020. The copyright holder for this preprint (which was not certified by peer review) is the author/funder, who has granted bioRxiv a license to display the preprint in perpetuity. It is made available under aCC-BY-ND 4.0 International license.

Park et al. | Functional connectome substrates of BMI variations

type neurons in the medial shell of the accumbens nucleus regulate palatable food intake. Int. J. Obes. 43, 917-927.

Van Essen, D.C., Glasser, M.F., Dierker, D.L., Harwell, J., and Coalson, T. (2012). Parcellations and hemispheric asymmetries of human cerebral cortex analyzed on surface-based atlases. Cereb. Cortex 22, 2241-2262.

Van Essen, D.C., Smith, S.M., Barch, D.M., Behrens, T.E.J., Yacoub, E., and Ugurbil, K. (2013). The WU-Minn Human Connectome Project: an overview. Neuroimage 80, 62-79.

Fischl, B. (2012). FreeSurfer. Neuroimage 62, 774-781.

Fischl, B., Sereno, M.I., and Dale, A.M. (1999a). Cortical surface-based analysis: II. Inflation, flattening, and a surface-based coordinate system. Neuroimage 9, 195-207.

Fischl, B., Sereno, M.I., Tootell, R.B.H., and Dale, A.M. (1999b). High-resolution inter-subject averaging and a surface-based coordinate system. Hum. Brain Mapp. 8, $272-284$.

Fulcher, B.D., Murray, J.D., Zerbi, V., and Wang, X.J. (2019). Multimodal gradients across mouse cortex. Proc. Natl. Acad. Sci. U. S. A. 116, 4689-4695.

García-García, I., Jurado, M.Á., Garolera, M., Segura, B., Sala-Llonch, R., Marqués-Iturria, I., Pueyo, R., Sender-Palacios, M.J., Vernet-Vernet, M., Narberhaus, A., et al. (2013). Alterations of the salience network in obesity: A resting-state fMRI study. Hum. Brain Mapp. 34, 2786-2797.

García-García, I., Jurado, M.Á., Garolera, M., Marqués-Iturria, I., Horstmann, A., Segura, B., Pueyo, R., Sender-Palacios, M.J., Vernet-Vernet, M., Villringer, A., et al. (2015). Functional network centrality in obesity: A resting-state and task fMRI study. Psychiatry Res. Neuroimaging $233,331-338$.

Glasser, M.F., and Van Essen, D.C. (2011). Mapping human cortical areas in vivo based on myelin content as revealed by T1- and T2-weighted MRI. J. Neurosci. 31, 11597-11616.

Glasser, M.F., Sotiropoulos, S.N., Wilson, J.A., Coalson, T.S., Fischl, B., Andersson, J.L., Xu, J., Jbabdi, S., Webster, M., Polimeni, J.R., et al. (2013). The minimal preprocessing pipelines for the Human Connectome Project. Neuroimage 80, 105-124.

Glasser, M.F., Goyal, M.S., Preuss, T.M., Raichle, M.E., and Van Essen, D.C. (2014). Trends and properties of human cerebral cortex: Correlations with cortical myelin content. Neuroimage 93, $165-175$.

Glasser, M.F., Coalson, T.S., Robinson, E.C., Hacker, C.D., Harwell, J., Yacoub, E., Ugurbil, K., Andersson, J., Beckmann, C.F., Jenkinson, M., et al. (2016). A multi-modal parcellation of human cerebral cortex. Nature 536, 171-178.

Goldstone, A.P., Prechtl De Hernandez, C.G., Beaver, J.D., Muhammed, K., Croese, C., Bell, G., Durighel, G., Hughes, E., Waldman, A.D., Frost, G., et al. (2009). Fasting biases brain reward systems towards high-calorie foods. Eur. J. Neurosci. 30, 1625-1635.

Gorgolewski, K.J., Fox, A.S., Chang, L., Schäfer, A., Arélin, K., Burmann, I., Sacher, J., and Margulies, D.S. (2014). Tight fitting genes: finding relations between statistical maps and gene expression patterns. In F1000Posters, p. 1607 (Poster).

Gorgolewski, K.J., Varoquaux, G., Rivera, G., Schwarz, Y., Ghosh, S.S., Maumet, C., Sochat, V. V., Nichols, T.E., Poldrack, R.A., Poline, J.B., et al. (2015). NeuroVault.Org: A web-based repository for collecting and sharing unthresholded statistical maps of the human brain. Front. 
bioRxiv preprint doi: https://doi.org/10.1101/2020.08.07.241794; this version posted August 7, 2020. The copyright holder for this preprint (which was not certified by peer review) is the author/funder, who has granted bioRxiv a license to display the preprint in perpetuity. It is made available under aCC-BY-ND 4.0 International license.

Park et al. | Functional connectome substrates of BMI variations

Neuroinform. 9, Article 8.

Gupta, A., Mayer, E.A., Labus, J.S., Bhatt, R.R., Ju, T., Love, A., Bal, A., Tillisch, K., Naliboff, B., Sanmiguel, C.P., et al. (2018). Sex Commonalities and Differences in Obesity-Related Alterations in Intrinsic Brain Activity and Connectivity. Obesity 26, 340-350.

Haak, K. V., and Beckmann, C.F. (2020). Understanding brain organisation in the face of functional heterogeneity and functional multiplicity. Neuroimage 220, 117061.

Hawrylycz, M.J., Lein, E.S., Guillozet-Bongaarts, A.L., Shen, E.H., Ng, L., Miller, J.A., Van De Lagemaat, L.N., Smith, K.A., Ebbert, A., Riley, Z.L., et al. (2012). An anatomically comprehensive atlas of the adult human brain transcriptome. Nature 489, 391-399.

Herrmann, M.J., Tesar, A.K., Beier, J., Berg, M., and Warrings, B. (2019). Grey matter alterations in obesity: A meta-analysis of whole-brain studies. Obes. Rev. 20, 464-471.

Hong, S.-J., Vos De Wael, R., Bethlehem, R.A.I., Lariviere, S., Paquola, C., Valk, S.L., Milham, M.P., Martino, A. Di, Margulies, D.S., Smallwood, J., et al. (2019). Atypical functional connectome hierarchy in autism. Nat. Commun. 10, 1022.

Huntenburg, J.M., Bazin, P.L., Goulas, A., Tardif, C.L., Villringer, A., and Margulies, D.S. (2017). A Systematic Relationship Between Functional Connectivity and Intracortical Myelin in the Human Cerebral Cortex. Cereb. Cortex 27, 981-997.

Huntenburg, J.M., Bazin, P.L., and Margulies, D.S. (2018). Large-Scale Gradients in Human Cortical Organization. Trends Cogn. Sci. 22, 21-31.

Jahanshad, N., Rajagopalan, P., Hua, X., Hibar, D.P., Nir, T.M., Toga, A.W., Jack, C.R., Saykin, A.J., Green, R.C., Weiner, M.W., et al. (2013). Genome-wide scan of healthy human connectome discovers SPON1 gene variant influencing dementia severity. Proc. Natl. Acad. Sci. U. S. A. 110, 4768-4773.

James, W.P.T. (2008). The epidemiology of obesity: The size of the problem. J. Intern. Med. 263, $336-352$.

Jenkinson, M., Beckmann, C.F., Behrens, T.E.J., Woolrich, M.W., and Smith, S.M. (2012). Fsl. Neuroimage 62, 782-790.

Jensen, M.D., Ryan, D.H., Apovian, C.M., Ard, J.D., Comuzzie, A.G., Donato, K.A., Hu, F.B., Hubbard, V.S., Jakicic, J.M., Kushner, R.F., et al. (2014). 2013 AHA/ACC/TOS guideline for the management of overweight and obesity in adults: A report of the American College of cardiology/American Heart Association task force on practice guidelines and the obesity society. Circulation 129, 102-138.

Kim, S.H., Park, B.Y., Byeon, K., Park, H., Kim, Y., Eun, Y.M., and Chung, J.H. (2019). The effects of high-frequency repetitive transcranial magnetic stimulation on resting-state functional connectivity in obese adults. Diabetes, Obes. Metab. 21, 1956-1966.

King, J.A., Frank, G.K.W., Thompson, P.M., and Ehrlich, S. (2018). Structural Neuroimaging of Anorexia Nervosa: Future Directions in the Quest for Mechanisms Underlying Dynamic Alterations. Biol. Psychiatry 83, 224-234.

Kohatsu, N.D., Tsai, R., Young, T., VanGilder, R., Burmeister, L.F., Stromquist, A.M., and Merchant, J.A. (2006). Sleep duration and body mass index in a rural population. Arch. Intern. Med. 166, 1701-1705. 
bioRxiv preprint doi: https://doi.org/10.1101/2020.08.07.241794; this version posted August 7, 2020. The copyright holder for this preprint (which was not certified by peer review) is the author/funder, who has granted bioRxiv a license to display the preprint in perpetuity. It is made available under aCC-BY-ND 4.0 International license.

Park et al. | Functional connectome substrates of BMI variations

Kuleshov, M. V., Jones, M.R., Rouillard, A.D., Fernandez, N.F., Duan, Q., Wang, Z., Koplev, S., Jenkins, S.L., Jagodnik, K.M., Lachmann, A., et al. (2016). Enrichr: a comprehensive gene set enrichment analysis web server 2016 update. Nucleic Acids Res. 44, W90-W97.

Langs, G., Golland, P., and Ghosh, S.S. (2015). Predicting Activation Across Individuals with Resting-State Functional Connectivity Based Multi-Atlas Label Fusion. In International Conference on Medical Image Computing and Computer-Assisted Intervention, pp. 313-320.

Larivière, S., Vos de Wael, R., Hong, S.-J., Paquola, C., Tavakol, S., Lowe, A.J., Schrader, D. V, and Bernhardt, B.C. (2019a). Multiscale Structure-Function Gradients in the Neonatal Connectome. Cereb. Cortex.

Larivière, S., Weng, Y., Wael, R.V. de, Frauscher, B., Wang, Z., Bernasconi, A., Bernasconi, N., Schrader, D. V., Zhang, Z., and Bernhardt, B.C. (2019b). Functional Connectome Contractions in Temporal Lobe Epilepsy. BioRxiv 756494.

Liao, X., Vasilakos, A. V., and He, Y. (2017). Small-world human brain networks: Perspectives and challenges. Neurosci. Biobehav. Rev. 77, 286-300.

Lips, M. a., Wijngaarden, M. a., Van Der Grond, J., Van Buchem, M. a., De Groot, G.H., Rombouts, S. a R.B., Pijl, H., and Veer, I.M. (2014). Resting-state functional connectivity of brain regions involved in cognitive control, motivation, and reward is enhanced in obese females. Am. J. Clin. Nutr. 100, 524-531.

Locke, A.E., Kahali, B., Berndt, S.I., Justice, A.E., Pers, T.H., Day, F.R., Powell, C., Vedantam, S., Buchkovich, M.L., Yang, J., et al. (2015). Genetic studies of body mass index yield new insights for obesity biology. Nature 518, 197-206.

Lowe, A.J., Paquola, C., Vos de Wael, R., Girn, M., Lariviere, S., Tavakol, S., Caldairou, B., Royer, J., Schrader, D. V., Bernasconi, A., et al. (2019). Targeting age-related differences in brain and cognition with multimodal imaging and connectome topography profiling. Hum. Brain Mapp. $40,5213-5230$.

Von Luxburg, U. (2007). A tutorial on spectral clustering. Stat. Comput. 17, 395-416.

Malik, V.S., Willett, W.C., and Hu, F.B. (2013). Global obesity: trends, risk factors and policy implications. Nat. Rev. Endocrinol. 9, 13-27.

Margulies, D.S., Ghosh, S.S., Goulas, A., Falkiewicz, M., Huntenburg, J.M., Langs, G., Bezgin, G., Eickhoff, S.B., Castellanos, F.X., Petrides, M., et al. (2016). Situating the default-mode network along a principal gradient of macroscale cortical organization. Proc. Natl. Acad. Sci. U. S. A. 113, 12574-12579.

Marqués-Iturria, I., Pueyo, R., Garolera, M., Segura, B., Junqué, C., García-García, I., José SenderPalacios, M., Vernet-Vernet, M., Narberhaus, A., Ariza, M., et al. (2013). Frontal cortical thinning and subcortical volume reductions in early adulthood obesity. Psychiatry Res. Neuroimaging 214, $109-115$.

Martin, L.E., Holsen, L.M., Chambers, R.J., Bruce, A.S., Brooks, W.M., Zarcone, J.R., Butler, M.G., and Savage, C.R. (2010). Neural mechanisms associated with food motivation in obese and healthy weight adults. Obesity 18, 254-260.

Matikainen-Ankney, B.A., and Kravitz, A. V. (2018). Persistent effects of obesity: a neuroplasticity hypothesis. Ann. N. Y. Acad. Sci. 1428, 221-239.

Medic, N., Ziauddeen, H., Ersche, K.D., Farooqi, I.S., Bullmore, E.T., Nathan, P.J., Ronan, L., and 
bioRxiv preprint doi: https://doi.org/10.1101/2020.08.07.241794; this version posted August $7,2020$. The copyright holder for this preprint (which was not certified by peer review) is the author/funder, who has granted bioRxiv a license to display the preprint in perpetuity. It is made available under aCC-BY-ND 4.0 International license.

Park et al. | Functional connectome substrates of BMI variations

Fletcher, P.C. (2016). Increased body mass index is associated with specific regional alterations in brain structure. Int. J. Obes. 40, 1177-1182.

Medic, N., Kochunov, P., Ziauddeen, H., Ersche, K.D., Nathan, P.J., Ronan, L., and Fletcher, P.C. (2019). BMI-related cortical morphometry changes are associated with altered white matter structure. Int. J. Obes. 43, 523-532.

Van Meer, F., Van der Laan, L.N., Eiben, G., Lissner, L., Wolters, M., Rach, S., Herrmann, M., Erhard, P., Molnar, D., Orsi, G., et al. (2019). Development and body mass inversely affect children's brain activation in dorsolateral prefrontal cortex during food choice. Neuroimage 201, 116016.

Mesulam, M.M. (1998). From sensation to cognition. Brain 121, 1013-1052.

Metzler-Baddeley, C., Mole, J.P., Leonaviciute, E., Sims, R., Kidd, E.J., Ertefai, B., Kelso-Mitchell, A., Gidney, F., Fasano, F., Evans, J., et al. (2018). Adipokines contribute to central-obesity related reductions in myelin-sensitive MRI indices in the fornix. BioRxiv.

Moore, C.F., Sabino, V., Koob, G.F., and Cottone, P. (2017). Neuroscience of compulsive eating behavior. Front. Neurosci. 11, 1-8.

Moreno-Lopez, L., Contreras-Rodriguez, O., Soriano-Mas, C., Stamatakis, E.A., and VerdejoGarcia, A. (2016). Disrupted functional connectivity in adolescent obesity. NeuroImage Clin. 12, 262-268.

Morys, F., Dadar, M., and Dagher, A. (2020). Obesity impairs cognitive function via metabolic syndrome and cerebrovascular disease: an SEM analysis in 15,000 adults from the UK Biobank. BioRxiv.

Müller, E., Munn, B., Hearne, L.J., Smith, J.B., Fulcher, B., Cocchi, L., and Shine, J.M. (2020). Core and Matrix Thalamic Sub-Populations Relate to Spatio-Temporal Cortical Connectivity Gradients. BioRxiv.

Murray, S., Tulloch, A., Gold, M.S., and Avena, N.M. (2014). Hormonal and neural mechanisms of food reward, eating behaviour and obesity. Nat. Rev. Endocrinol. 10, 540-552.

Olivo, G., Wiemerslage, L., Swenne, I., Zhukowsky, C., Salonen-Ros, H., Larsson, E.M., Gaudio, S., Brooks, S.J., and Schiöth, H.B. (2017). Limbic-thalamo-cortical projections and reward-related circuitry integrity affects eating behavior: A longitudinal DTI study in adolescents with restrictive eating disorders. PLoS One 12, e0172129.

Opel, N., Redlich, R., Grotegerd, D., Dohm, K., Haupenthal, C., Heindel, W., Kugel, H., Arolt, V., and Dannlowski, U. (2015). Enhanced neural responsiveness to reward associated with obesity in the absence of food-related stimuli. Hum. Brain Mapp. 36, 2330-2337.

Opel, N., Thalamuthu, A., Milaneschi, Y., Grotegerd, D., Flint, C., Leenings, R., Goltermann, J., Richter, M., Hahn, T., Woditsch, G., et al. (2020). Brain structural abnormalities in obesity: relation to age, genetic risk, and common psychiatric disorders : Evidence through univariate and multivariate mega-analysis including 6420 participants from the ENIGMA MDD working group. Mol. Psychiatry.

Van Opstal, A.M., Van Den Berg-Huysmans, A.A., Hoeksma, M., Blonk, C., Pijl, H., Rombouts, S.A.R.B., and van Der Grond, J. (2018). The effect of consumption temperature on the homeostatic and hedonic responses to glucose ingestion in the hypothalamus and the reward system. Am. J.

Clin. Nutr. 107, 20-25. 
Ottino-González, J., Baggio, H.C., Jurado, M.A., Segura, B., Caldú, X., Prats-Soteras, X., Tor, C., Sender-Palacios, M.J., Miró, N., Sánchez-Garre, C., et al. (2020). Alterations in brain network organization in adults with obesity as compared to healthy-weight individuals and seniors. BioRxiv.

Paquola, C., Vos De Wael, R., Wagstyl, K., Bethlehem, R.A.I., Hong, S.J., Seidlitz, J., Bullmore, E.T., Evans, A.C., Misic, B., Margulies, D.S., et al. (2019a). Microstructural and functional gradients are increasingly dissociated in transmodal cortices. PLoS Biol. 17, e3000284.

Paquola, C., Bethlehem, R.A., Seidlitz, J., Wagstyl, K., Romero-Garcia, R., Whitaker, K.J., Vos de Wael, R., Williams, G.B., Vértes, P.E., Margulies, D.S., et al. (2019b). Shifts in myeloarchitecture characterise adolescent development of cortical gradients. Elife 8, 1-23.

Paquola, C., Seidlitz, J., Benkarim, O., Royer, J., Klimes, P., Bethlehem, R.A.I., Lariviere, S., Wael, R.V. de, Hall, J.A., Frauscher, B., et al. (2020). The cortical wiring scheme of hierarchical information processing. BioRxiv.

Park, B., Seo, J., Yi, J., and Park, H. (2015). Structural and functional brain connectivity of people with obesity and prediction of body mass index using connectivity. PLoS One 10, e0141376.

Park, B., Seo, J., and Park, H. (2016). Functional brain networks associated with eating behaviors in obesity. Sci. Rep. 6, 23891.

Park, B., Hong, J., and Park, H. (2017). Neuroimaging biomarkers to associate obesity and negative emotions. Sci. Rep. 7, 1-7.

Park, B., Moon, T., and Park, H. (2018). Dynamic functional connectivity analysis reveals improved association between brain networks and eating behaviors compared to static analysis. Behav. Brain Res. 337, 114-121.

Park, B., Chung, C.-S., Lee, M.J., and Park, H. (2019a). Accurate neuroimaging biomarkers to predict body mass index in adolescents: a longitudinal study. Brain Imaging Behav.

Park, B., Byeon, K., and Park, H. (2019b). FuNP (Fusion of Neuroimaging Preprocessing) Pipelines: A Fully Automated Preprocessing Software for Functional Magnetic Resonance Imaging. Front. Neuroinform. 13, Article 5.

Park, B., Hong, S.-J., Valk, S.L., Paquola, C., Benkarim, O., Bethlehem, R.A.I., Martino, A. Di, Milham, M., Gozzi, A., Yeo, B.T.T., et al. (2020a). Connectome and microcircuit models implicate atypical subcortico-cortical interactions in autism pathophysiology. BioRxiv.

Park, B., Bethlehem, R.A.I., Paquola, C., Larivière, S., Cruces, R.R., Wael, R.V. de, Consortium, N. in P.N. (NSPN), Bullmore, E.T., and Bernhardt, B.C. (2020b). Macroscale connectome manifold expansion in adolescence. BioRxiv.

Power, J.D., Schlaggar, B.L., Lessov-Schlaggar, C.N., and Petersen, S.E. (2013). Evidence for hubs in human functional brain networks. Neuron 79, 798-813.

Raji, C.A., Ho, A.J., Parikshak, N., Becker, J.T., Lopez, O.L., Kuller, L.H., Hua, X., and Leow, A.D. (2010). Brain Structure and Obesity. Hum. Brain Mapp. 31, 353-364.

Reed, J.A., Einstein, G., Hahn, E., Hooker, S.P., Gross, V.P., and Kravitz, J. (2010). Examining the impact of integrating physical activity on fluid intelligence and academic performance in an elementary school setting: A preliminary investigation. J. Phys. Act. Heal. 7, 343-351.

Ronan, L., Alexander-Bloch, A., and Fletcher, P.C. (2019). Childhood Obesity, Cortical Structure, and Executive Function in Healthy Children. Cereb. Cortex 1-10. 
bioRxiv preprint doi: https://doi.org/10.1101/2020.08.07.241794; this version posted August $7,2020$. The copyright holder for this preprint (which was not certified by peer review) is the author/funder, who has granted bioRxiv a license to display the preprint in perpetuity. It is made available under aCC-BY-ND 4.0 International license.

Park et al. | Functional connectome substrates of BMI variations

Rubinov, M., and Sporns, O. (2010). Complex network measures of brain connectivity: uses and interpretations. Neuroimage 52, 1059-1069.

Salimi-Khorshidi, G., Douaud, G., Beckmann, C.F., Glasser, M.F., Griffanti, L., and Smith, S.M. (2014). Automatic denoising of functional MRI data: Combining independent component analysis and hierarchical fusion of classifiers. Neuroimage 90, 449-468.

Schaefer, A., Kong, R., Gordon, E.M., Laumann, T.O., Zuo, X.-N., Holmes, A.J., Eickhoff, S.B., and Yeo, B.T.T. (2018). Local-Global Parcellation of the Human Cerebral Cortex from Intrinsic Functional Connectivity MRI. Cereb. Cortex 28, 3095-3114.

Sena, A., Sarliève, L.L., and Rebel, G. (1985). Brain myelin of genetically obese mice. J. Neurol. Sci. 68, 233-244.

Shaw, M.E., Sachdev, P.S., Abhayaratna, W., Anstey, K.J., and Cherbuin, N. (2018). Body mass index is associated with cortical thinning with different patterns in mid- and late-life. Int. J. Obes. $42,455-461$.

Shott, M.E., Cornier, M., Mittal, V. a, Pryor, T.L., Orr, J.M., Brown, M.S., and Frank, G.K.W. (2015). Orbitofrontal cortex volume and brain reward response in obesity. Int. J. Obes. 39, 214 221.

Sporns, O. (2013). Structure and function of complex brain networks. Dialogues Clin. Neurosci. 15, $247-262$.

Steward, T., Miranda-Olivos, R., Soriano-Mas, C., and Fernández-Aranda, F. (2019a).

Neuroendocrinological mechanisms underlying impulsive and compulsive behaviors in obesity: a narrative review of fMRI studies. Rev. Endocr. Metab. Disord. 20, 263-272.

Steward, T., Juaneda-Seguí, A., Mestre-Bach, G., Martínez-Zalacaín, I., Vilarrasa, N., JiménezMurcia, S., Fernández-Formoso, J.A., Veciana de las Heras, M., Custal, N., Virgili, N., et al. (2019b). What Difference Does it Make? Risk-Taking Behavior in Obesity after a Loss is Associated with Decreased Ventromedial Prefrontal Cortex Activity. J. Clin. Med. 8, 1551.

Stoeckel, L.E., Weller, R.E., Cook, E.W., Twieg, D.B., Knowlton, R.C., and Cox, J.E. (2008). Widespread reward-system activation in obese women in response to pictures of high-calorie foods. Neuroimage 41, 636-647.

Tenenbaum, J.B., Silva, V. de, and Langford, J.C. (2000). A Global Geometric Framework for Nonlinear Dimensionality Reduction. Science (80-. ). 290, 2319-2323.

Thompson, W.H., and Fransson, P. (2016). On Stabilizing the Variance of Dynamic Functional Brain Connectivity Time Series. Brain Connect. 6, 735-746.

Timper, K., and Brüning, J.C. (2017). Hypothalamic circuits regulating appetite and energy homeostasis: Pathways to obesity. DMM Dis. Model. Mech. 10, 679-689.

Vainik, U., Dagher, A., Dubé, L., and Fellows, L.K. (2013). Neurobehavioural correlates of body mass index and eating behaviours in adults: A systematic review. Neurosci. Biobehav. Rev. 37, 279-299.

Vainik, U., Baker, T.E., Dadar, M., Zeighami, Y., Michaud, A., Zhang, Y., García Alanis, J.C., Misic, B., Louis Collins, D., and Dagher, A. (2018). Neurobehavioral correlates of obesity are largely heritable. Proc. Natl. Acad. Sci. U. S. A. 115, 9312-9317.

Val-Laillet, D., Aarts, E., Weber, B., Ferrari, M., Quaresima, V., Stoeckel, L.E., Alonso-Alonso, 
bioRxiv preprint doi: https://doi.org/10.1101/2020.08.07.241794; this version posted August 7, 2020. The copyright holder for this preprint (which was not certified by peer review) is the author/funder, who has granted bioRxiv a license to display the preprint in perpetuity. It is made available under aCC-BY-ND 4.0 International license.

Park et al. | Functional connectome substrates of BMI variations

M., Audette, M., Malbert, C.H., and Stice, E. (2015). Neuroimaging and neuromodulation approaches to study eating behavior and prevent and treat eating disorders and obesity. NeuroImage Clin. 8, 1-31.

Vargas, P.A., Flores, M., and Robles, E. (2014). Sleep quality and body mass index in college students: The role of sleep disturbances. J. Am. Coll. Heal. 62, 534-541.

Veit, R., Kullmann, S., Heni, M., Machann, J., Häring, H.U., Fritsche, A., and Preissl, H. (2014). Reduced cortical thickness associated with visceral fat and BMI. NeuroImage Clin. 6, 307-311.

Verdejo-Román, J., Vilar-López, R., Navas, J.F., Soriano-Mas, C., and Verdejo-García, A. (2017). Brain reward system's alterations in response to food and monetary stimuli in overweight and obese individuals. Hum. Brain Mapp. 38, 666-677.

Vong, L., Ye, C., Yang, Z., Choi, B., Chua, S., and Lowell, B.B. (2011). Leptin Action on GABAergic Neurons Prevents Obesity and Reduces Inhibitory Tone to POMC Neurons. Neuron $71,142-154$.

Vos de Wael, R., Benkarim, O., Paquola, C., Lariviere, S., Royer, J., Tavakol, S., Xu, T., Hong, S.J., Valk, S.L., Misic, B., et al. (2020). BrainSpace: a toolbox for the analysis of macroscale gradients in neuroimaging and connectomics datasets. Commun. Biol. 3, 103.

Vos De Wael, R., Larivière, S., Caldairou, B., Hong, S.J., Margulies, D.S., Jefferies, E., Bernasconi, A., Smallwood, J., Bernasconi, N., and Bernhardt, B.C. (2018). Anatomical and microstructural determinants of hippocampal subfield functional connectome embedding. Proc. Natl. Acad. Sci. U. S. A. $115,10154-10159$.

Wang, L., Zhu, C., He, Y., Zang, Y., Cao, Q., Zhang, H., Zhong, Q., and Wang, Y. (2009). Altered small-world brain functional networks in children with attention-deficit/hyperactivity disorder. Hum. Brain Mapp. 30, 638-649.

Westwater, M.L., Vilar-López, R., Ziauddeen, H., Verdejo-García, A., and Fletcher, P.C. (2019). Combined effects of age and BMI are related to altered cortical thickness in adolescence and adulthood. Dev. Cogn. Neurosci. 40.

Whitmer, R., Gunderson, E., Quesenberry, C., Zhou, J., and Yaffe, K. (2007). Body Mass Index in Midlife and Risk of Alzheimer Disease and Vascular Dementia. Curr. Alzheimer Res. 4, 103-109.

World Health Organization (2020). Obesity and overweight.

Xiao, G., Burguet, J., Kawaguchi, R., Havton, L.A., and Hinman, J.D. (2018). Obesity restricts oligodendrocyte maturation and impedes repair after white matter stroke. BioRxiv.

Xu, J., Li, Y., Lin, H., Sinha, R., and Potenza, M.N. (2013). Body mass index correlates negatively with white matter integrity in the fornix and corpus callosum: A diffusion tensor imaging study. Hum. Brain Mapp. 34, 1044-1052.

Yeo, B.T.T., Krienen, F.M., Sepulcre, J., Sabuncu, M.R., Lashkari, D., Hollinshead, M., Roffman, J.L., Smoller, J.W., Zollei, L., Polimeni, J.R., et al. (2011). The organization of the human cerebral cortex estimated by intrinsic functional connectivity. J. Neurophysiol. 106, 1125-1165.

Zhao, X., Liu, Y., Wang, X., Liu, B., Xi, Q., Guo, Q., Jiang, H., Jiang, T., and Wang, P. (2012). Disrupted small-world brain networks in moderate Alzheimer's disease: A resting-state fMRI study. PLoS One 7, e33540.

Ziauddeen, H., Alonso-Alonso, M., Hill, J.O., Kelley, M., and Khan, N.A. (2015). Obesity and the 
bioRxiv preprint doi: https://doi.org/10.1101/2020.08.07.241794; this version posted August 7, 2020. The copyright holder for this preprint (which was not certified by peer review) is the author/funder, who has granted bioRxiv a license to display the preprint in perpetuity. It is made available under aCC-BY-ND 4.0 International license.

Park et al. | Functional connectome substrates of BMI variations

Neurocognitive Basis of Food Reward and the Control of Intake. Adv. Nutr. 6, 474-486. 
bioRxiv preprint doi: https://doi.org/10.1101/2020 08.07.241794 t this version posted August 7, 2020. The copyright holder for this preprint (which was not certified by peer review) is the author/funder, who has granted bioRxiv a license to display the preprint in perpetuity. It is made available under aCC-BY-ND 4.0 International license.

Park et al. | Functional connectome substrates of BMI variations

Correlation between manifold eccentricity and BMI according to functional community

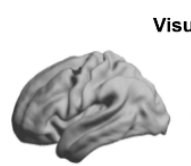

Visual
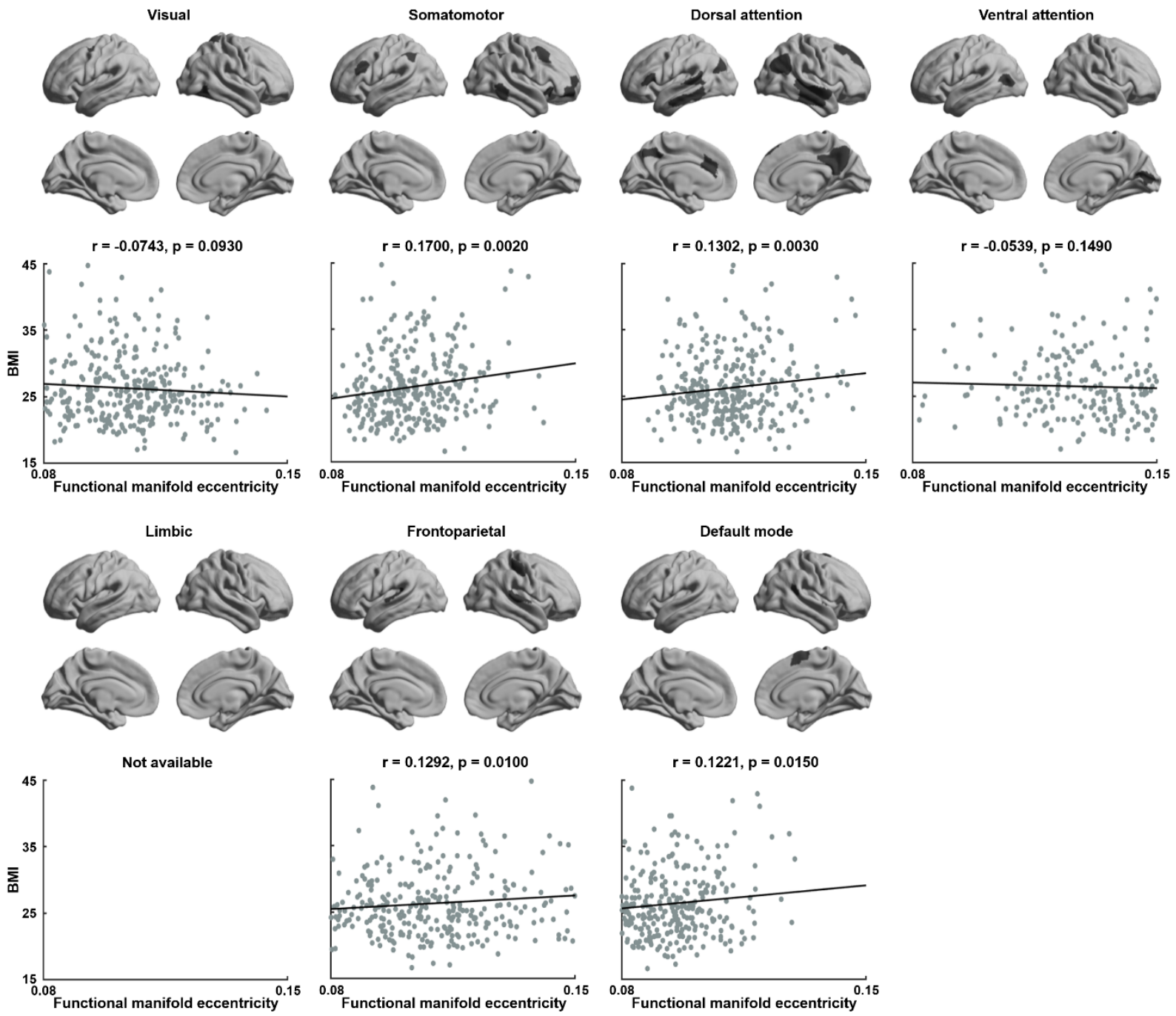

Fig. S1 | Association between BMI and functional manifold eccentricity. Linear correlations between BMI and functional manifold eccentricity according to intrinsic functional communities (Yeo et al., 2011). 
bioRxiv preprint doi: https://doi.org/10.1101/2020.08.07.241794 t this version posted August 7, 2020. The copyright holder for this preprint (which was not certified by peer review) is the author/funder, who has granted bioRxiv a license to display the preprint in perpetuity. It is made available under aCC-BY-ND 4.0 International license.

Park et al. | Functional connectome substrates of BMI variations

A. Modules

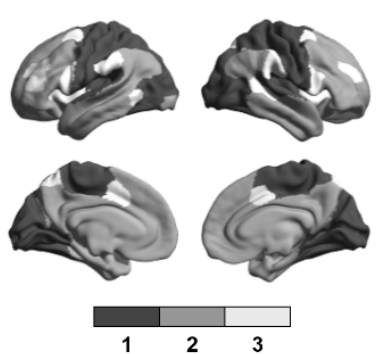

B. Modular measures

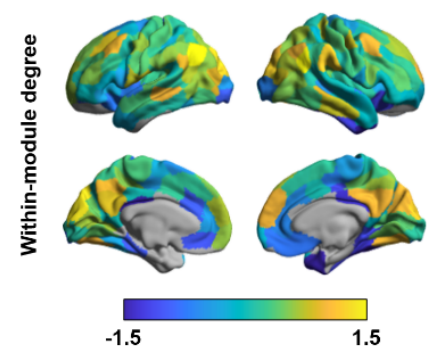

$-1.5$

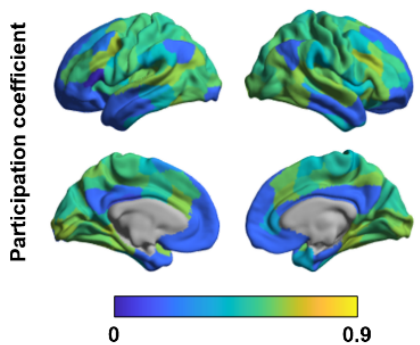

C. Association between manifold eccentricity and modular measures
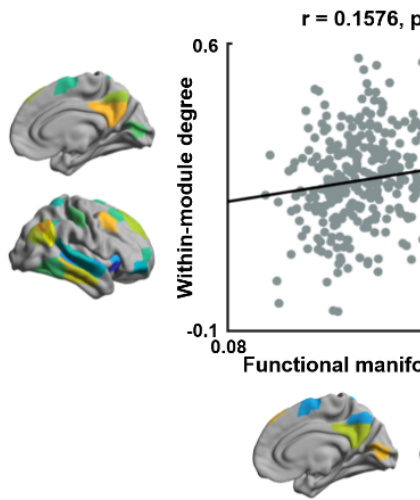

$0.1576, p=0.0020$

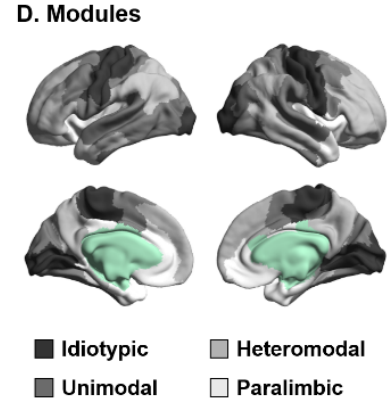

E. Modular measures
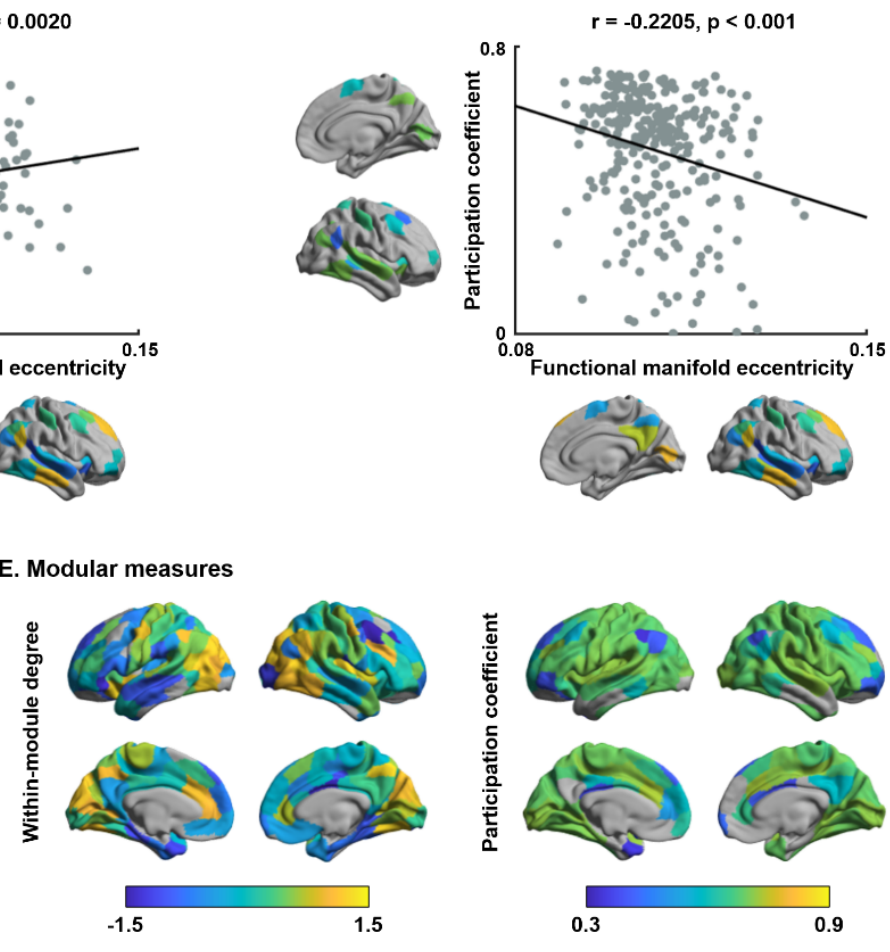

F. Association between manifold eccentricity and modular measures
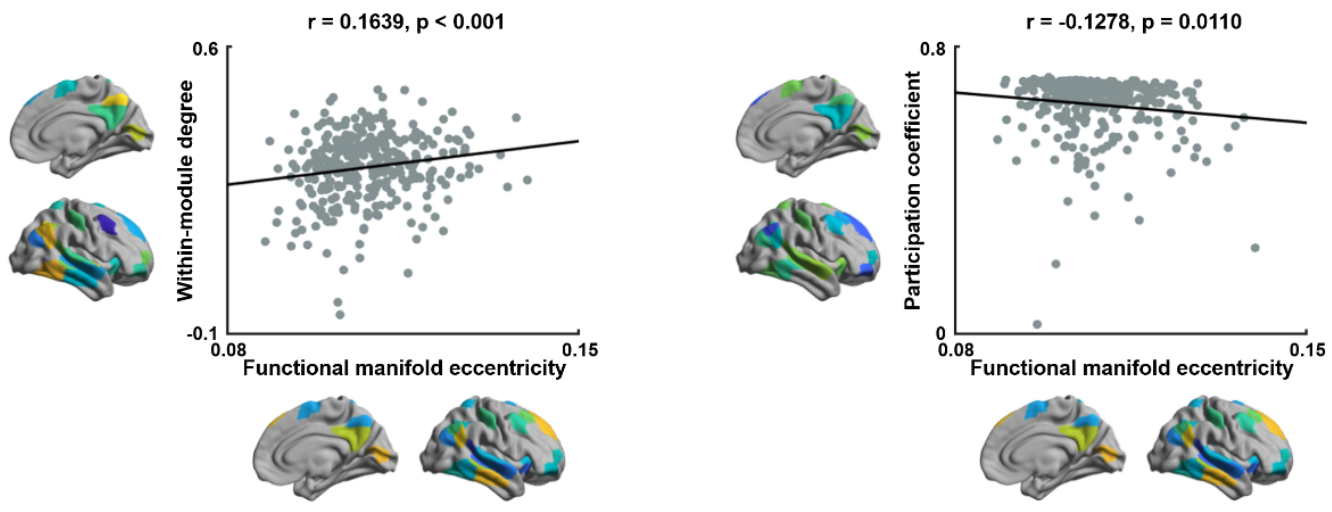

Fig. S2 | Manifold eccentricity and modular measures. (A-C) Modules defined using Louvain community detection (Blondel et al., 2008) and (D-F) cortical hierarchy (Mesulam, 1998). For details, see Fig. 3. 
bioRxiv preprint doi: https://doi org/10.1101/2020.08.07.241794 t this version posted August 7, 2020. The copyright holder for this preprint (which was not certified by peer review) is the author/funder, who has granted bioRxiv a license to display the preprint in perpetuity. It is made available under aCC-BY-ND 4.0 International license.

Park et al. | Functional connectome substrates of BMI variations

Different types of brain structure associated with BMI
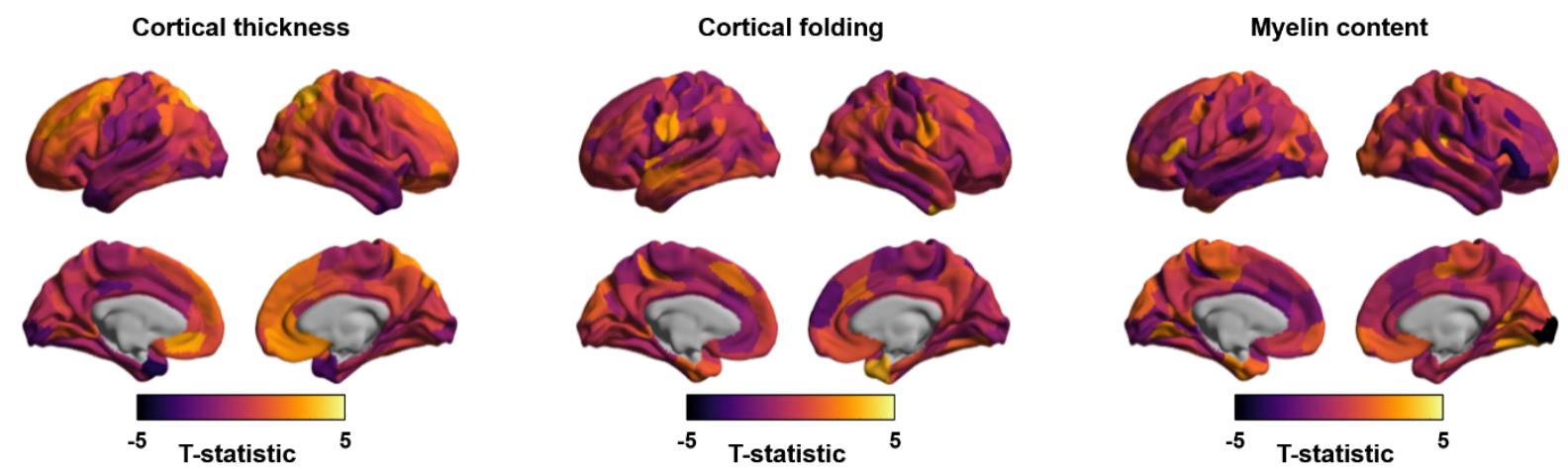

Fig. S3 | Effects of brain structures. The t-statistics of the association between brain structures (i.e., cortical thickness, cortical folding, and myelin content) and BMI. 
bioRxiv preprint doi: https://doi.org/10.1101/2020.08.07 241794 this version posted August 7,2020 . The copyright holder for this preprint (which was not certified by peer review) is the author/funder, who has granted bioRxiv a license to display the preprint in perpetuity. It is made available under aCC-BY-ND 4.0 International license.

Park et al. | Functional connectome substrates of BMI variations

A. Functional connectome manifold associated with BMI HCP discovery
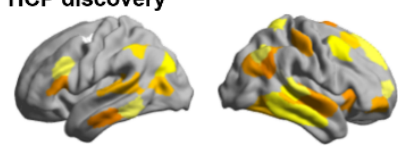

HCP validation
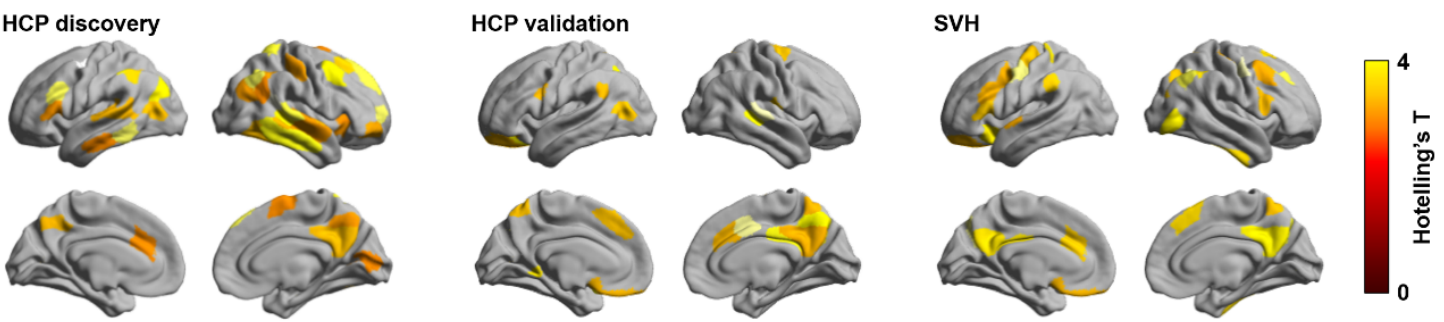

B. Functional connectome manifold associated with BMI controlling for head motion
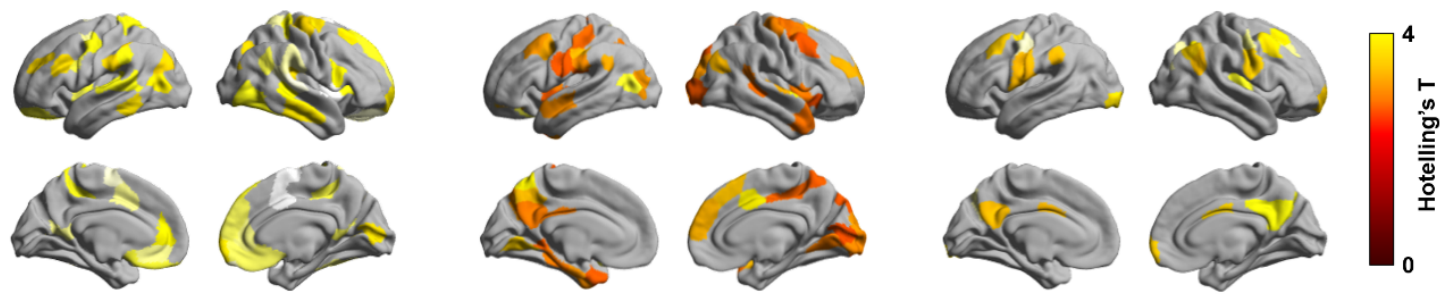

C. Functional connectome manifold associated with BMI controlling for fluid intelligence and sleep quality
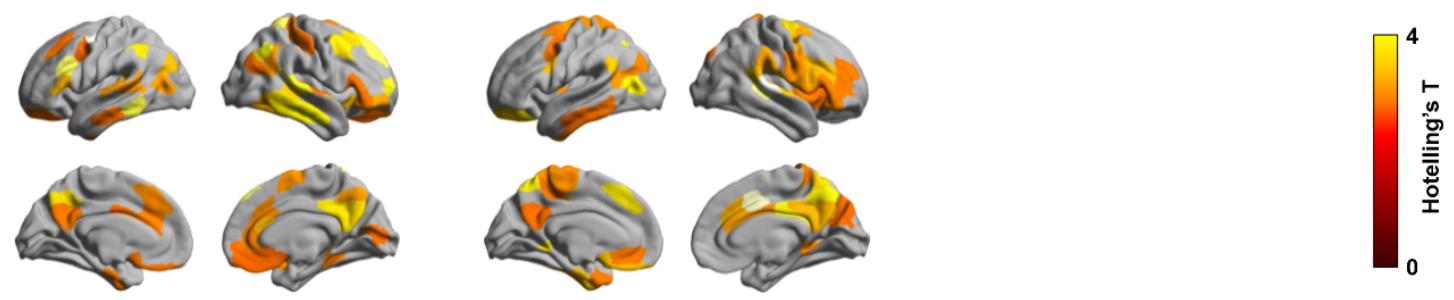

Fig. S4 | Head motion effect. (A) Multivariate association between the three manifolds and BMI without and (B) with controlling for head motion. (C) Multivariate association results after controlling for fluid intelligence and sleep quality. Abbreviations: BMI, body mass index; HCP, human connectome project; SVH, St. Vincent's Hospital. 
bioRxiv preprint doi: https://doi.org/10.1101/2020.08 07 241794 this version posted August 7, 2020. The copyright holder for this preprint (which was not certified by peer review) is the author/funder, who has granted bioRxiv a license to display the preprint in perpetuity. It is made available under aCC-BY-ND 4.0 International license.

Park et al. | Functional connectome substrates of BMI variations

A. Template manifold
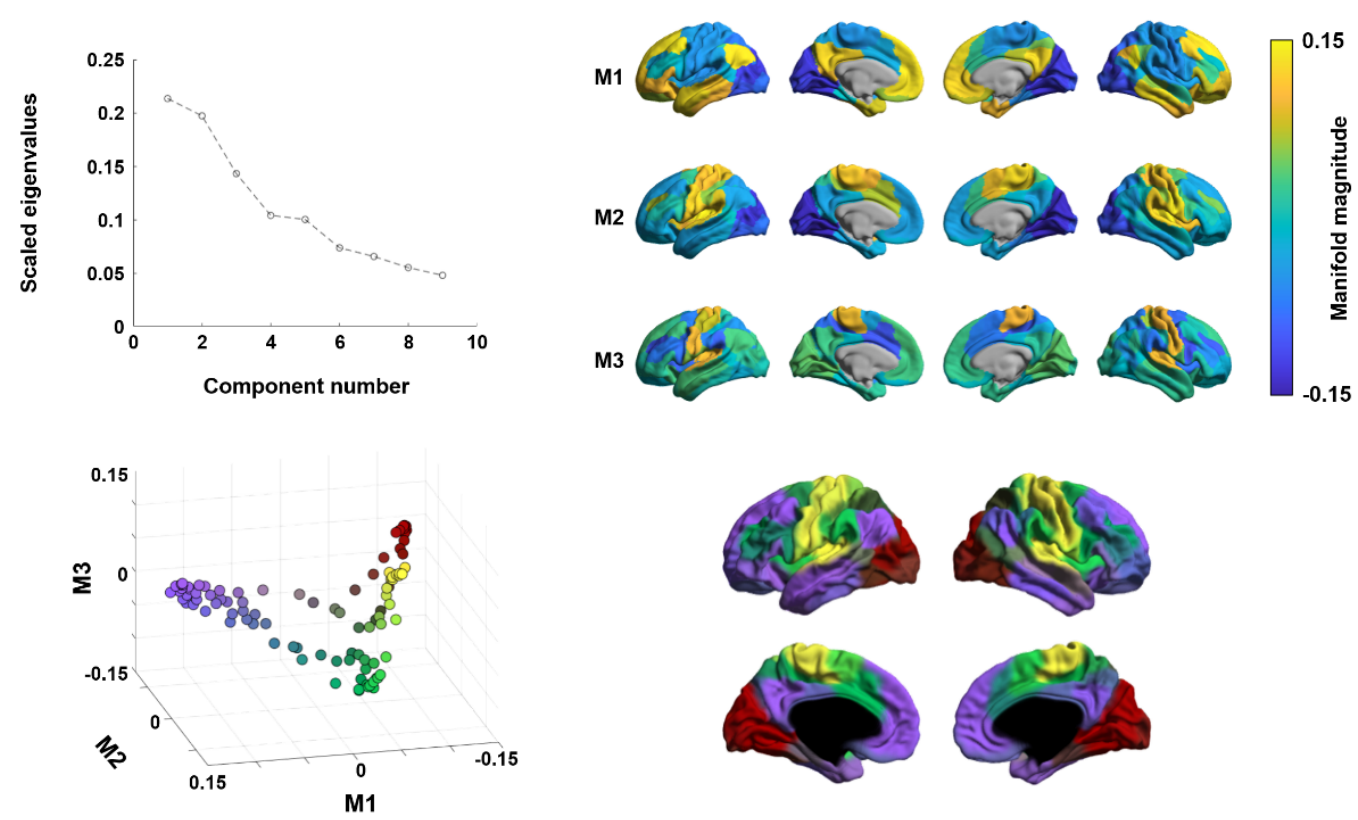

B. Functional connectome manifold associated with BMI
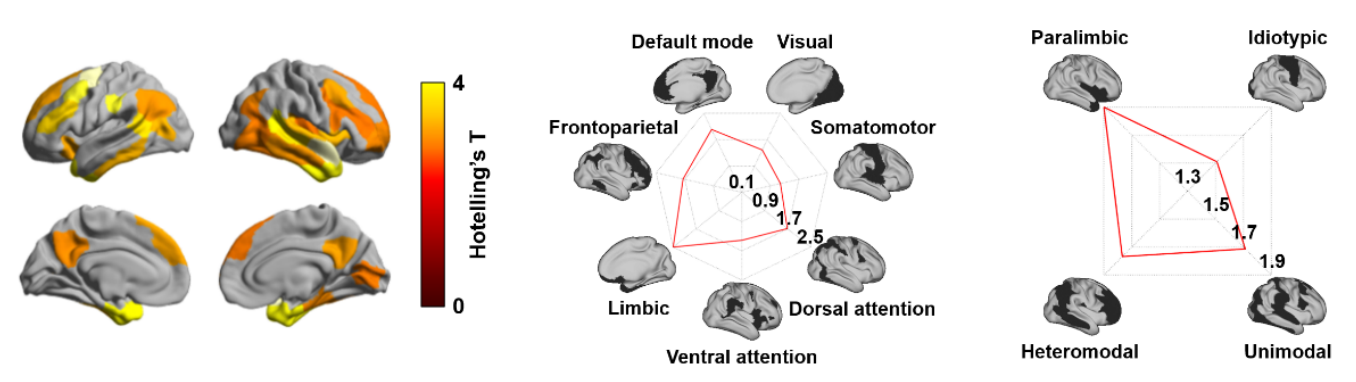

C. Functional manifold eccentricity and correlation with BMI
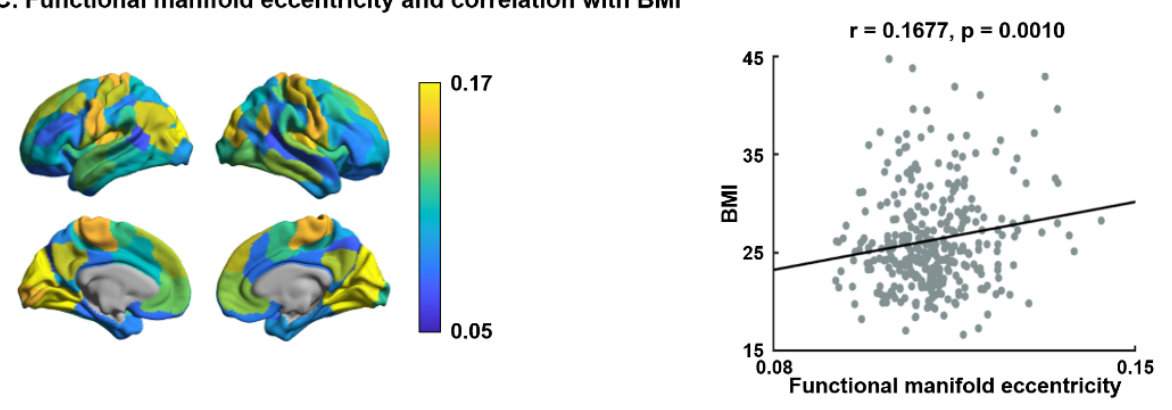

Fig. S5 | Results based on the Schaefer 100 atlas. For details, see Fig. 1 and 2. 
bioRxiv preprint doi: https://doi.org/10.1101/2020 08 07.241794 t this version posted August 7, 2020. The copyright holder for this preprint (which was not certified by peer review) is the author/funder, who has granted bioRxiv a license to display the preprint in perpetuity. It is made available under aCC-BY-ND 4.0 International license.

Park et al. | Functional connectome substrates of BMI variations

A. Template manifold
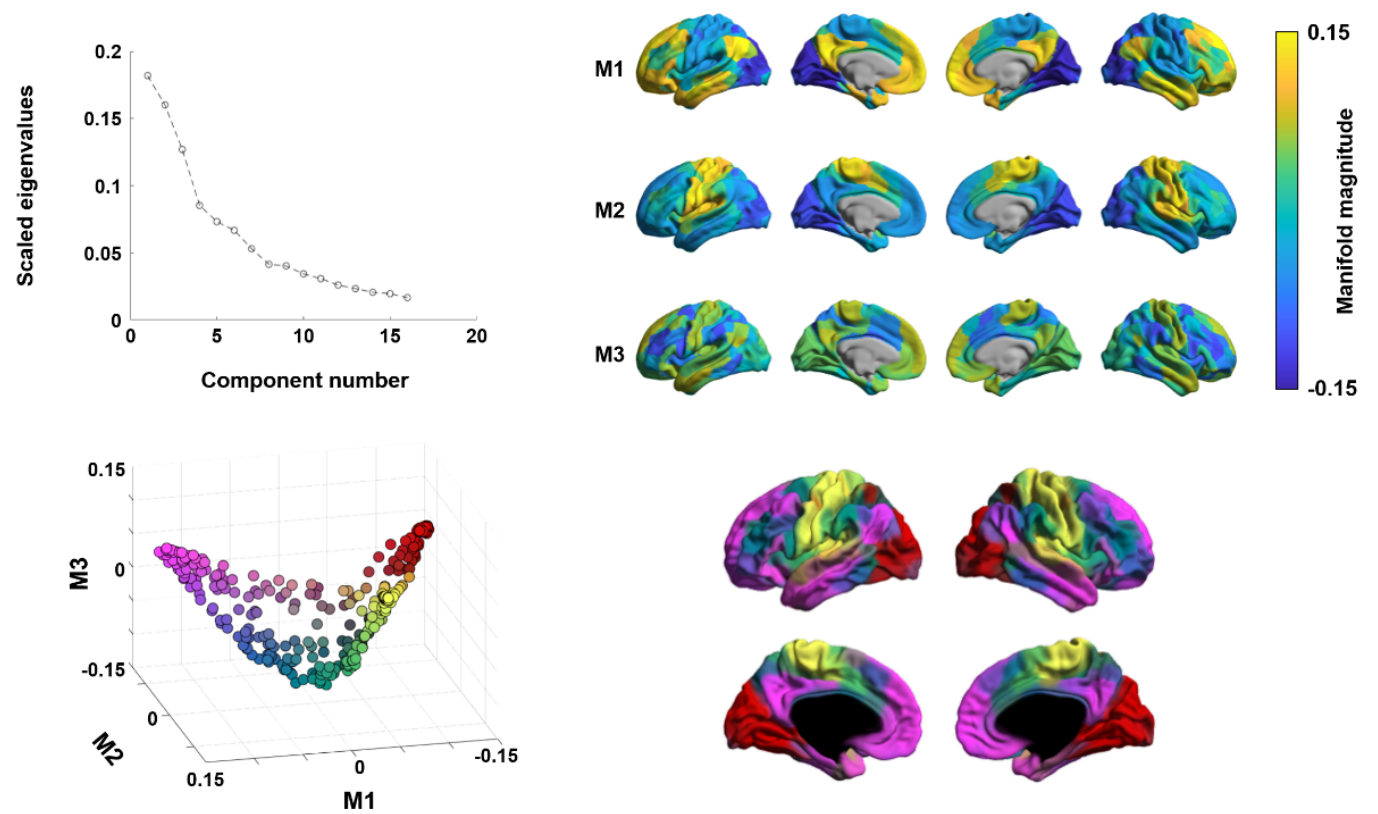

B. Functional connectome manifold associated with BMI
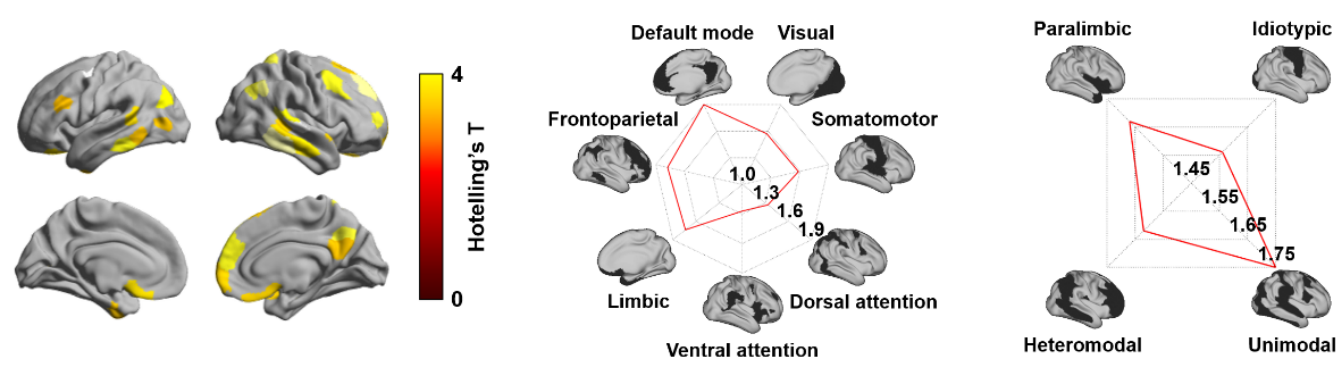

C. Functional manifold eccentricity and correlation with BMI
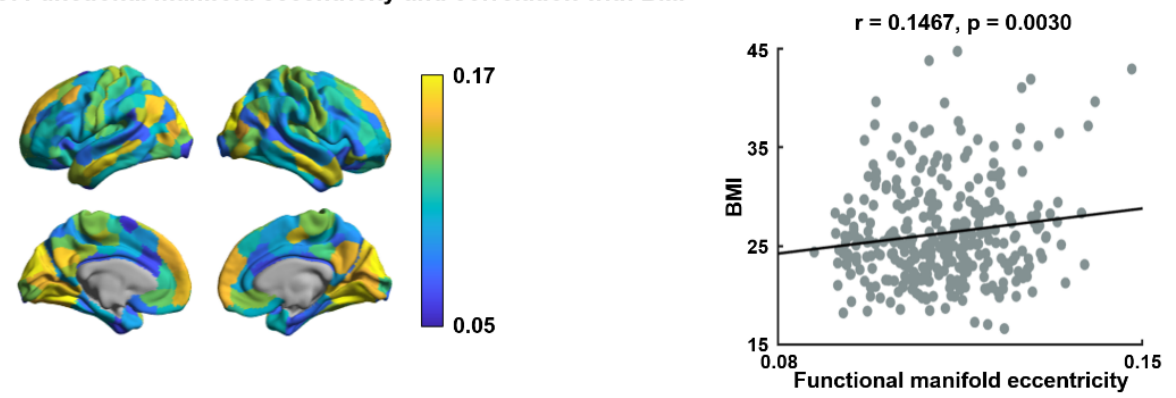

Fig. S6 | Results based on the Schaefer 300 atlas. For details, see Fig. 1 and 2. 
bioRxiv preprint doi: https://doi.org/10.1101/2020.08 07 241794 this version posted August 7, 2020. The copyright holder for this preprint (which was not certified by peer review) is the author/funder, who has granted bioRxiv a license to display the preprint in perpetuity. It is made available under aCC-BY-ND 4.0 International license.

Park et al. | Functional connectome substrates of BMI variations

A. Template manifold
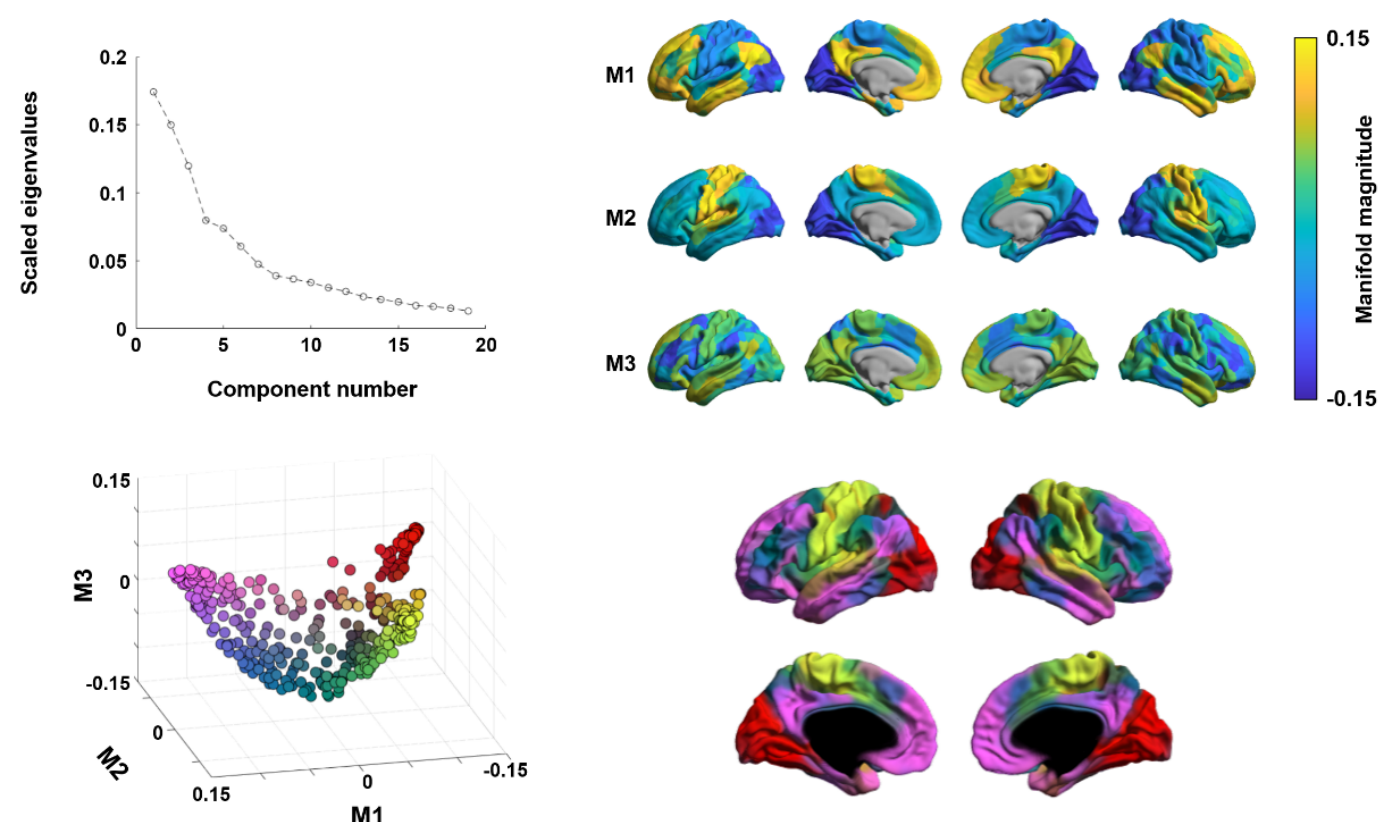

B. Functional connectome manifold associated with BMI
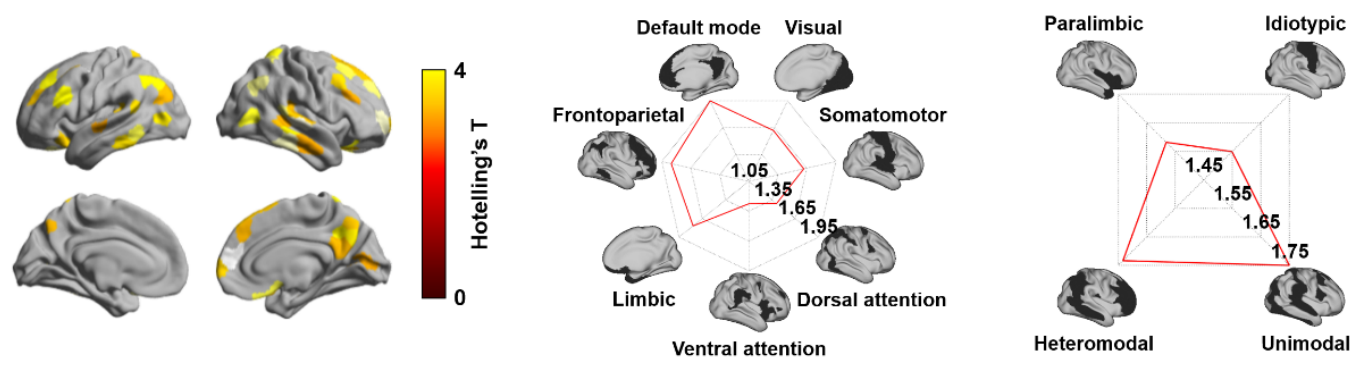

C. Functional manifold eccentricity and correlation with BMI
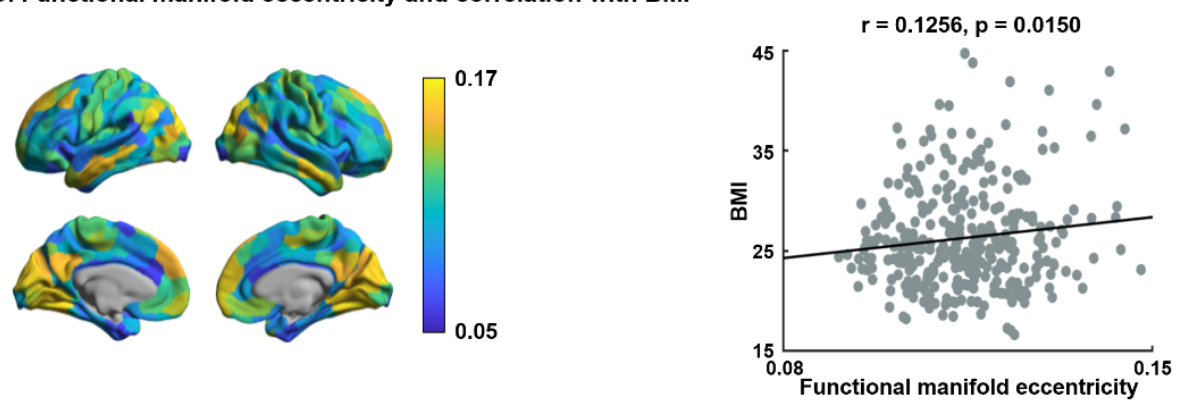

Fig. S7 | Results based on the Schaefer 400 atlas. For details, see Fig. 1 and 2. 

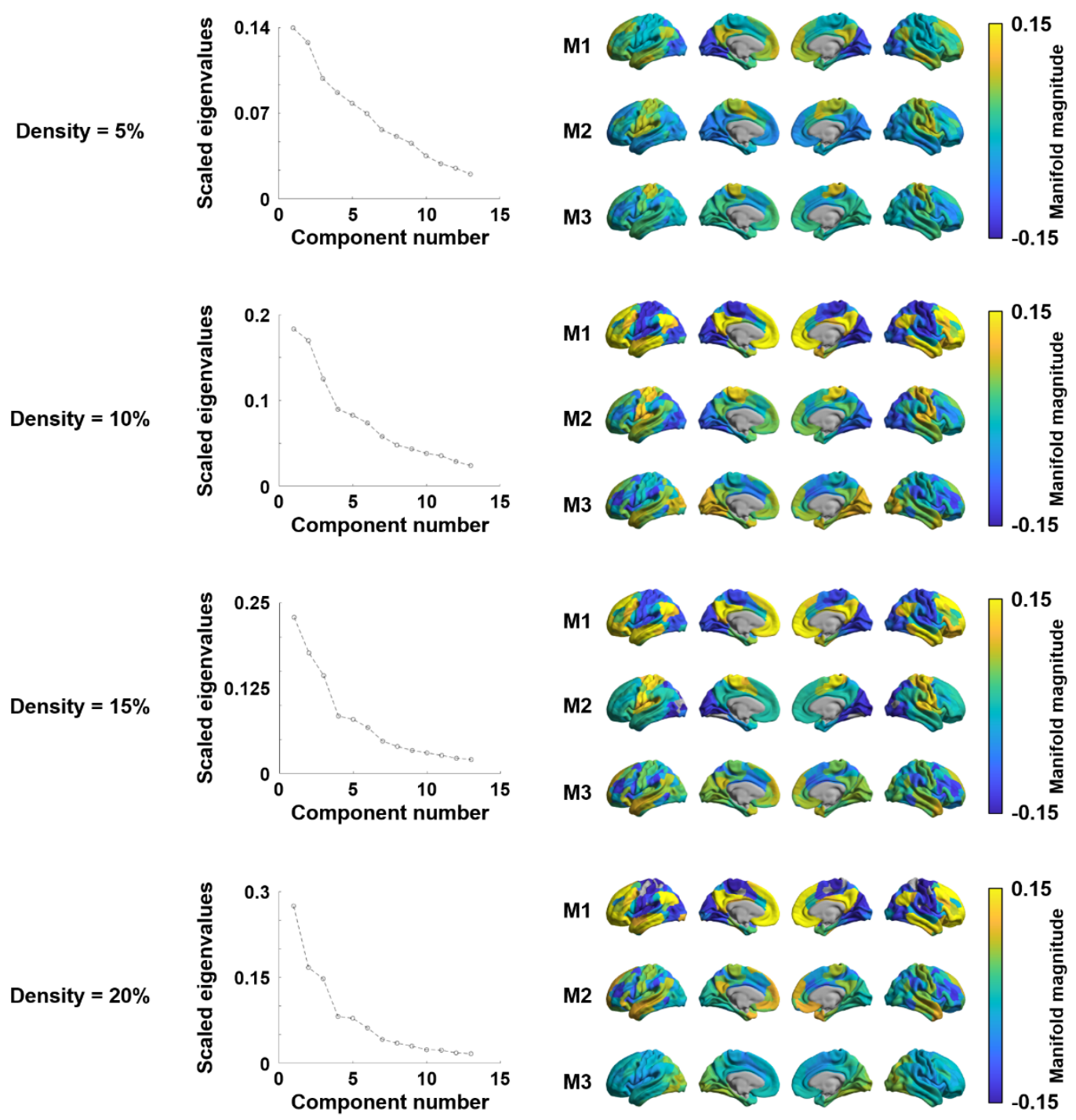

Fig. S8 | Functional manifolds with different connectome densities. Connectome density from 5\% to $20 \%$ with $5 \%$ interval was applied. 


\section{A. Between-group comparison}
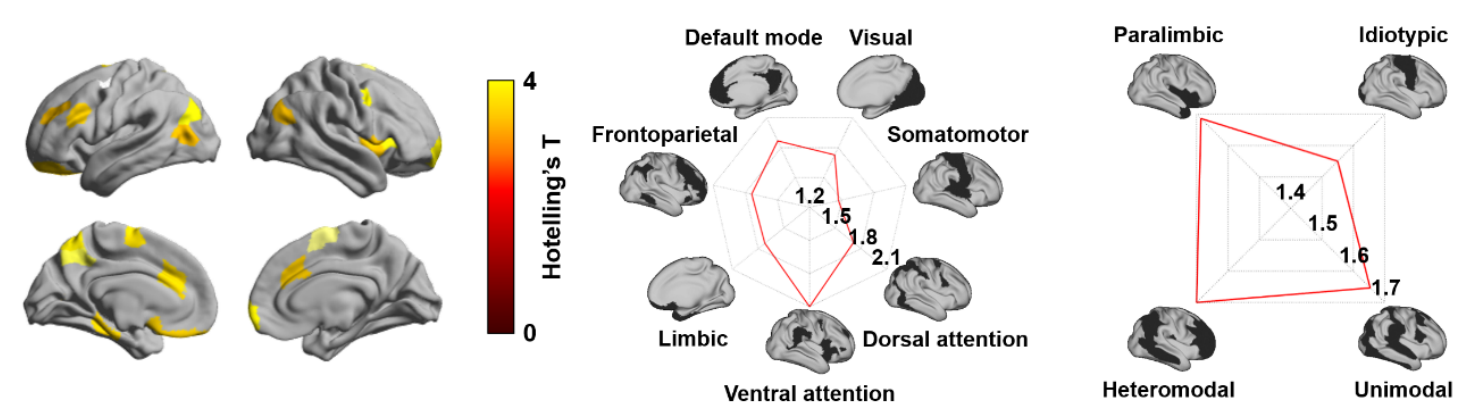

B. Functional connectome manifold associated with weight
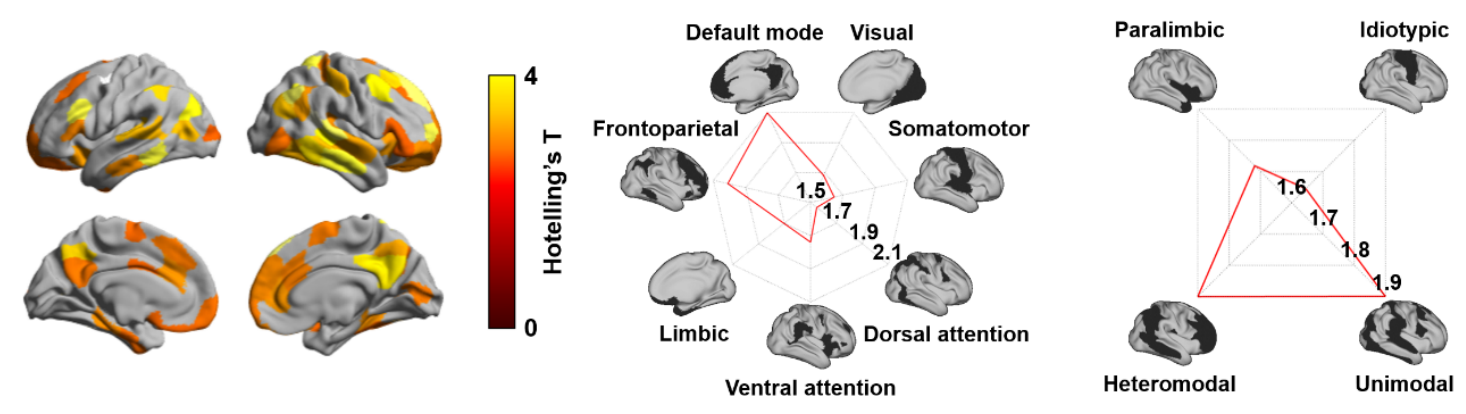

Fig. S9 | Results based on different approaches. (A) The t-statistics of the identified regions that showed significant between-group differences in functional connectome manifolds between individuals with healthy $(18.5 \leq \mathrm{BMI}<25)$ and non-healthy weight $(\mathrm{BMI} \geq 25)$. (B) Those for the multivariate association analyses between functional connectome manifolds and weight. 
bioRxiv preprint doi: https://doi.org/10.1101/2020.08 07.241794 t this version posted August 7 2020. The copyright holder for this preprint (which was not certified by peer review) is the author/funder, who has granted bioRxiv a license to display the preprint in perpetuity. It is made available under aCC-BY-ND 4.0 International license.

Park et al. | Functional connectome substrates of BMI variations

A. Mean functional connectome manifold
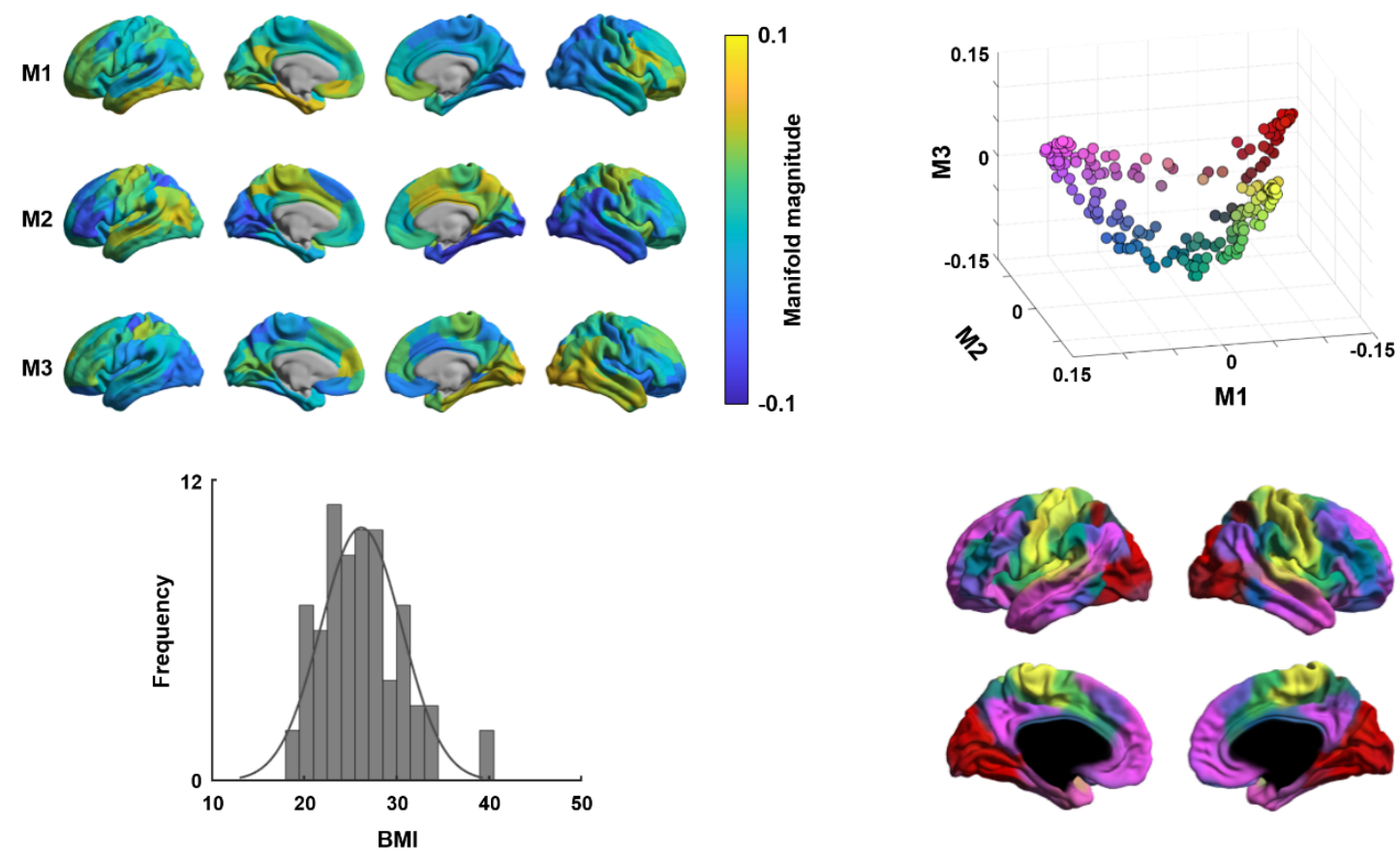

B. Functional connectome manifold associated with BMI
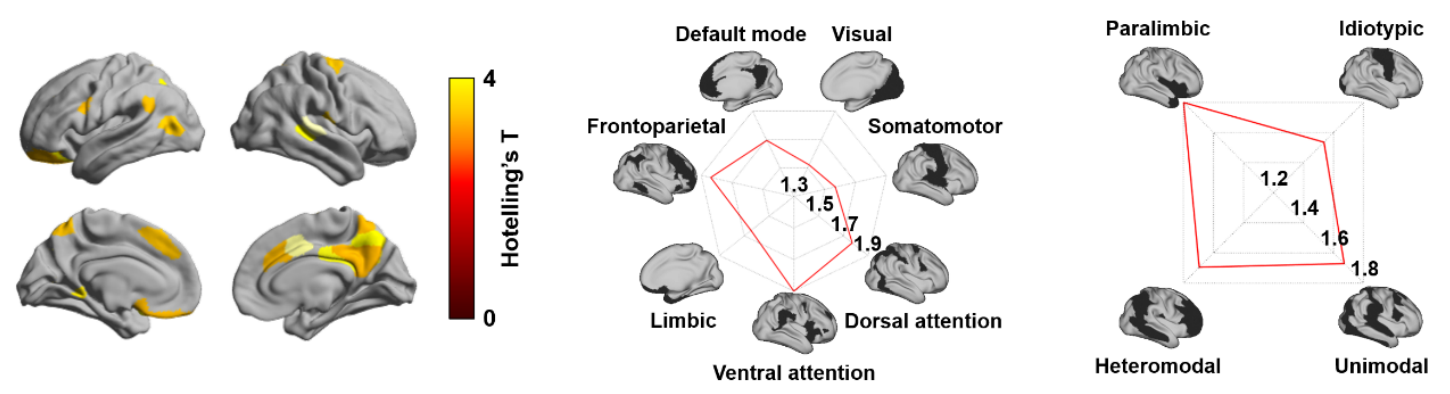

C. Functional manifold eccentricity and correlation with BMI
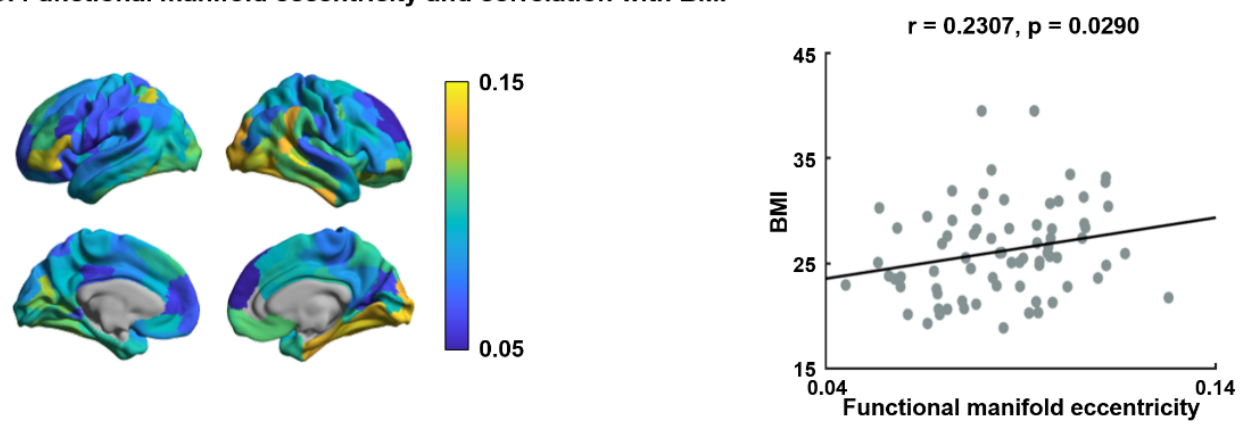

Fig. S10 | The results derived using HCP validation data. For details, see Fig. 1 and 2. 
bioRxiv preprint doi: https://doi.org/10.1101/2020.08 07 241794 this version posted August 7 2020. The copyright holder for this preprint (which was not certified by peer review) is the author/funder, who has granted bioRxiv a license to display the preprint in perpetuity. It is made available under aCC-BY-ND 4.0 International license.

Park et al. | Functional connectome substrates of BMI variations

A. Mean functional connectome manifold
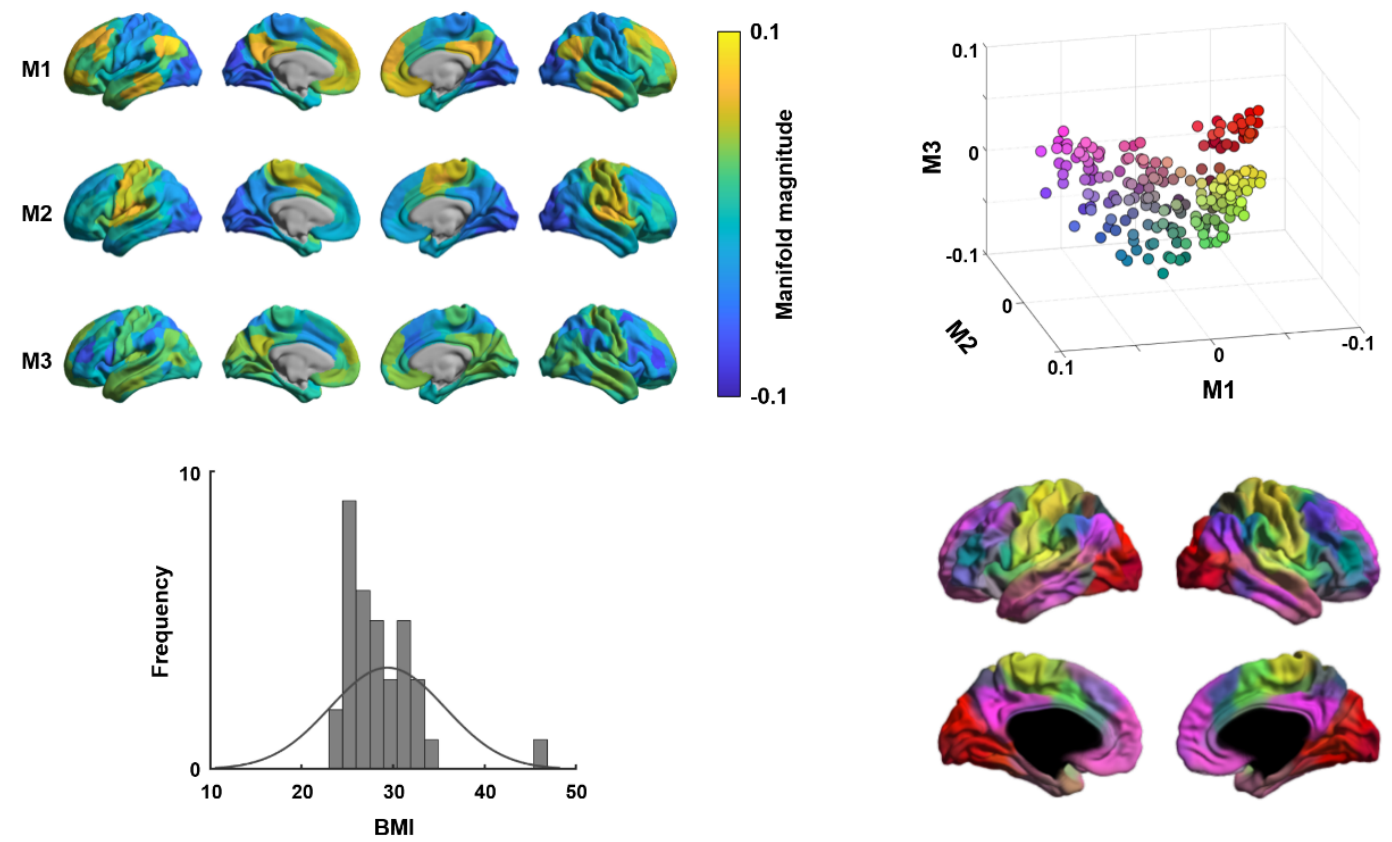

B. Functional connectome manifold associated with BMI
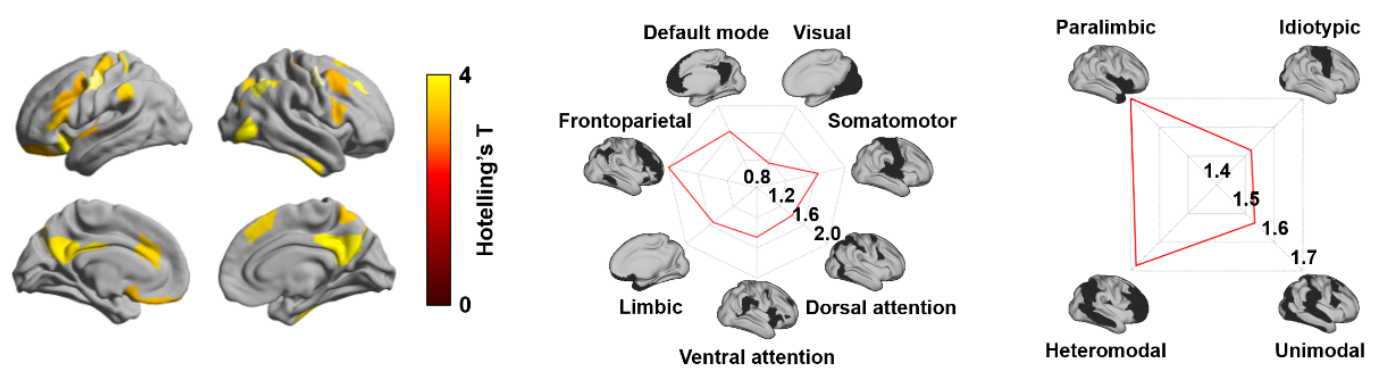

C. Functional manifold eccentricity and correlation with BMI
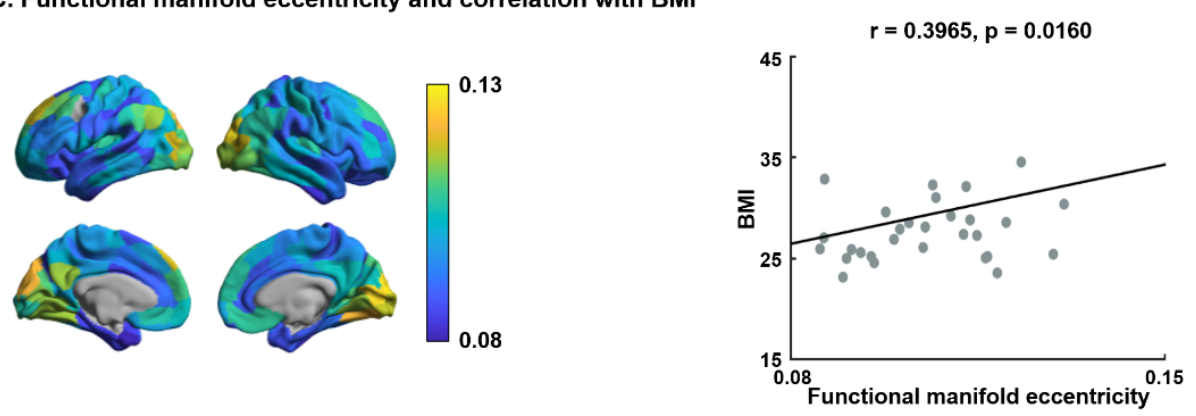

Fig. S11 | The results derived using an independent data from SVH. For details, see Fig. 1 and 2. 
bioRxiv preprint doi: https://doi.org/10.1101/2020.08.07.241794: this version posted August 7, 2020. The copyright holder for this preprint (which was not certified by peer review) is the author/funder, who has granted bioRxiv a license to display the preprint in perpetuity. It is made available under aCC-BY-ND 4.0 International license.

Park et al. | Functional connectome substrates of BMI variations

Data S1 | Significant gene lists correlated with functional connectome manifolds associated with BMI. Gene symbol with name and t-statistic as well as FDR corrected p-value are reported in the Supplementary Data file (Supplementary_Data1.xlsx). 